\title{
Short-Term Compressive Strength of Fly Ash and Waste Glass Alkali-Activated Cement-Based Binder Mortars with Two Biopolymers
}

\author{
Z. Abdollahnejad ${ }^{1}$; M. Kheradmand ${ }^{2}$; and F. Pacheco-Torgal ${ }^{3}$
}

\begin{abstract}
The Roadmap to a Resource Efficient Europe aims that by 2020, waste will be managed as a resource. Thus materials that have the ability for the reuse of several types of wastes, such as alkali-activated cement-based binders (AACBs), will merit special attention. Some wastes like fly ash deserve special attention because they are generated in high amounts and have a very low reuse rate. This paper reports experimental results regarding the influence of the mix design of fly ash and waste glass AACB mortars containing two different biopolymers (carrageenan and xanthan) on their short-term mechanical performance. Microstructure and cost analysis are also included. The results show that a mixture of $80 \%$ fly ash, $10 \%$ waste glass, and $10 \%$ calcium hydroxide activated with an alkaline activator has the highest compressive strength. The results also show that the mortars with minor biopolymer carrageenan content are associated with a relevant increase in compressive strength and that the use of $0.1 \%$ of carrageenan leads to optimum compressive strength in most mixtures. The use of xanthan shows no beneficial effects on the compressive strength of AACB mortars. Several mixtures with xanthan even show a reduction in the compressive strength. DOI: 10.1061/(ASCE)MT.1943-5533.0001920. (C) 2017 American Society of Civil Engineers.
\end{abstract}

Author keywords: Waste reuse; Fly ash; Waste glass; Alkali-activated cement-based binders (AACB); Biopolymers; Mechanical strength; Cost analysis.

\section{Introduction}

The flagship initiative Roadmap to a Resource Efficient Europe has proven that resource efficiency is very important not only from an environmental point of view but also to boost industrial competitiveness in the EU. According to the Roadmap, "By 2020, waste is managed as a resource" [COM 571 (COM 2011)]. This is of paramount importance in the European context of a circular economy and zero waste target that may lead to an overall savings potential of 630 billion Euro per year for European industry and can also create more than 180,000 direct jobs in the EU by 2030 [COM 398 (COM 2014)]. Thus materials that have the ability for the reuse of several types of wastes, such as alkali-activated cement-based binders (AACBs) (Fig. 1), will merit special attention. AACBs are produced though the reaction of an aluminosilicate precursor with an activator, usually composed of hydroxide, silicate, carbonate, or sulfate, leading to the formation an amorphous aluminosilicate gel and secondary nanocrystalline zeolitelike structures. The activation of higher calcium content-based precursors, which are not classified as geopolymers, generates $\mathrm{C}-\mathrm{A}-\mathrm{S}-\mathrm{H}$ gel that can coexist with minor secondary N-A-S-H gel (Provis 2014). These materials show important features but also some shortcomings that need to be addressed in order to compete against portland cement (Provis et al. 2008;

${ }^{1}$ C-TAC Research Centre, Univ. of Minho, 4800-058 Guimarães, Portugal. E-mail: ohammadkeradmand99@hotmail.com

${ }^{2}$ C-TAC Research Centre, Univ. of Minho, 4800-058 Guimarães, Portugal. E-mail: tolumavas@gmail.com

${ }^{3}$ C-TAC Research Centre, Univ. of Minho, 4800-058 Guimarães, Portugal; SHRC, Univ. of Sungkyunkwan, Suwon, Republic of Korea (corresponding author). E-mail: torgal@civil.uminho.pt

Note. This manuscript was submitted on October 11, 2016; approved on December 16, 2016; published online on March 29, 2017. Discussion period open until August 29, 2017; separate discussions must be submitted for individual papers. This paper is part of the Journal of Materials in Civil Engineering, (C) ASCE, ISSN 0899-1561.
Pacheco-Torgal et al. 2012, 2016). AACBs have a particular ability for the reuse of several types of wastes (Payá et al. 2014; Chinprasirt and Cao 2014; Bernal et al. 2016). Some wastes like fly ash deserve special attention because they are generated in high amounts and have a very low reuse rate. The United States has a reuse rate for fly ash of around 50\%, meaning that 30 million tons of fly ash are not reused annually (ACAA 2016). Also recent studies (Bernal et al. 2016) concerning waste geopolymerization confirm that India and the Middle East currently report fly ash utilization rates below $20 \%$. Other recent works confirm the importance of further studies regarding the development of geopolymers based on fly ash precursors (Zhuang et al. 2016). Waste glass is also a waste that is generated in relevant quantities and that merits increased recycling efforts. In Portugal approximately 425,000 t of waste glass were produced and only $192,000 \mathrm{t}$ of them were recycled. Approximately $373 \mathrm{t}$ of waste glass are generated daily in Hong Kong. According to some authors (Rashad 2014; Yu et al. 2016), the total amount of waste glass generated in the EU-27 in 2007 was $25.8 \mathrm{Mt}$. The use of waste glass in alkali-activated binders is especially interesting because its high $\mathrm{SiO}_{2}$ content allows for a reduction on the content of sodium silicate, thus reducing the cost of this binder, which constitutes one of the AACBs' shortcomings (Pacheco-Torgal et al. 2016). This reason justified recent studies on alkali-activated materials containing waste glass (Redden and Neithalath 2014; Martinez-Lopez and Escalante-Garcia 2016; Wang et al. 2016). In this context, this paper reports results of compressive strength, X-ray diffraction (XRD), scanning electron microscope (SEM), and cost analyses of several fly ash and waste glass AACB mortars.

\section{Experimental Program}

\section{Materials and Mix Design}

The AACB mortars were prepared by mixing fly ash, calcium hydroxide $(\mathrm{CH})$ milled waste glass $(\mathrm{MG})$, fine aggregate, and 


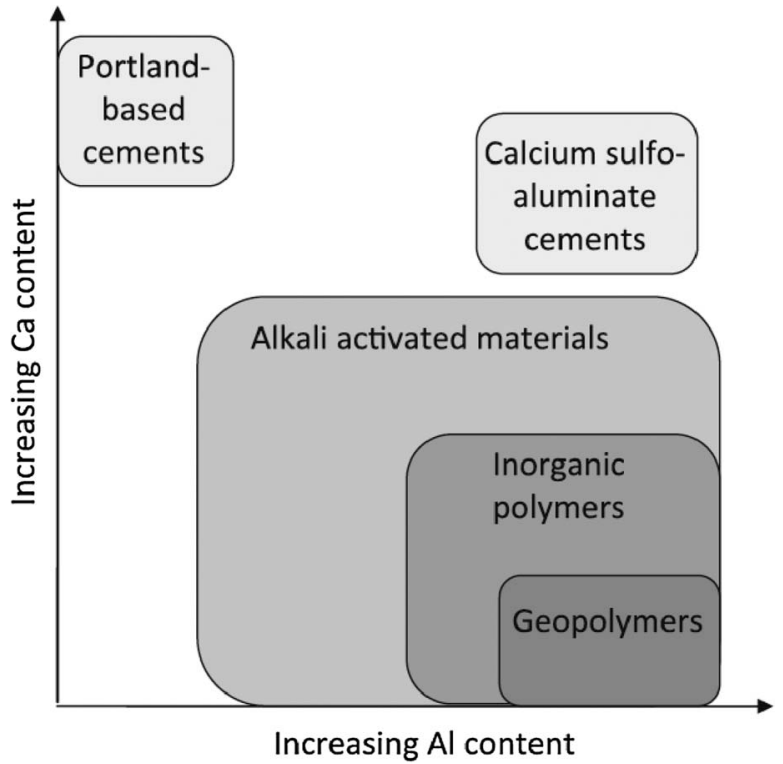

Fig. 1. Classification of different subsets of AAMs, with comparisons to OPC and calcium sulfoaluminate binder chemistry (reprinted from Springer, Waste and Biomass Valorization, "Chemical Research and Climate Change as Drivers in the Commercial Adoption of Alkali Activated Materials," Vol. 1, Issue 1, pp. 145-155, 2010, J. Van Deventer, J. Provis, P. Duxson, and D. Brice, with permission of Springer)

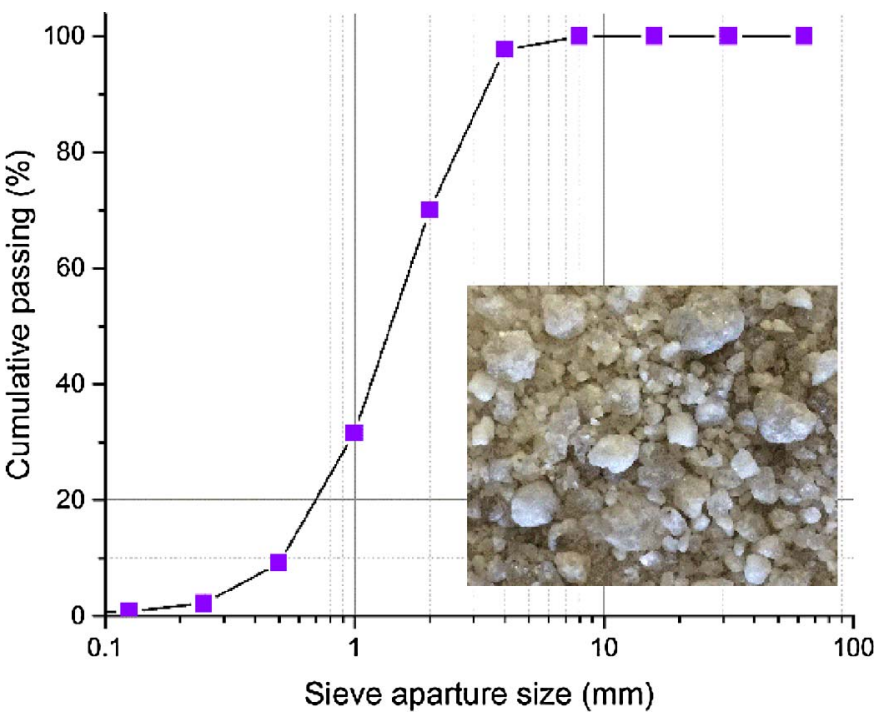

Fig. 2. Distribution of particle size of aggregates (image by M. Kheradmand)

an alkaline activator. The sand was used as inert filler provided from MIBAL (Minas de Barqueiros, S.A. Portugal). The sand was sieved (4.75- and 0.6-mm mesh) in order to remove dust particles. Fig. 2 shows the particle size of the sand. A sand:binder ratio of 4 was used. The fly ash was obtained from the PEGO Thermal Power Plant in Portugal and it was classified as Class F according to the ASTM-C618 standard (ASTM 2015). Table 1 presents the chemical composition and physical properties of fly ash. The sodium silicate liquid was supplied by MARCANDE (Portugal). The calcium hydroxide used in this study was a commercial Portuguese one (Lusical H100) with a chemical composition of $\mathrm{Ca}(\mathrm{OH})_{2} \geq$ $93 \%$ and $\mathrm{MgO} \leq 3$. Milled glass was used to partially replace fly
Table 1. Chemical Composition and Physical Properties of Fly Ash

\begin{tabular}{lc}
\hline Parameter & \% by weight \\
\hline Composition & \\
$\mathrm{SiO}_{2}$ & 60.81 \\
$\mathrm{Al}_{2} \mathrm{O}_{3}$ & 22.68 \\
$\mathrm{Fe}_{2} \mathrm{O}_{3}$ & 7.64 \\
$\mathrm{MgO}$ & 2.24 \\
$\mathrm{Na} O$ & 1.45 \\
$\mathrm{CaO}$ & 1.01 \\
$\mathrm{TiO}_{2}$ & 1.46 \\
$\mathrm{~K}_{2} \mathrm{O}$ & 2.70 \\
Physical properties & \\
Specific gravity & 2.30 \\
Specific surface $\left(\mathrm{cm}^{2} / \mathrm{g}\right)$ & 3,430 \\
\hline
\end{tabular}

ash. Waste glass powder was prepared from glass bottles, where the bottles were ground for $1 \mathrm{~h}$ in a ball mill in the laboratory. The density for the milled glass was $1.27 \mathrm{~g} / \mathrm{cm}^{3}$. The alkaline activator was prepared by mixing $\mathrm{NaOH}$ solution and sodium silicate solution in different mass ratios: $1,1.5$, and 2. An alkaline activator: binder ratio of 0.8 was used. The chemical composition of the sodium silicate was of $13.5 \% \mathrm{Na}_{2} \mathrm{O}, 58.7 \% \mathrm{SiO}_{2}$, and $45.2 \% \mathrm{H}_{2} \mathrm{O}$. Solid sodium hydroxide were obtained from commercially available product of ERCROS (S.A., Spain). Distilled water was used to dissolve the sodium hydroxide flakes to avoid the effect of unknown contaminants in the mixing water. The sodium hydroxide $(\mathrm{NaOH})$ solution was prepared by dissolving $\mathrm{NaOH}$ pellets in water to obtain concentrations of 4 and $8 \mathrm{~mol} / \mathrm{L}$ cooled at room temperature. Two biopolymers, carrageenan and xanthan, were provided by Melbourne Food Depot (2016). Xanthan is a natural polysaccharide, which is produced by a biotechnological process involving fermentation of glucose or sucrose by the Xanthomonas campestris bacterium. Carrageenan is a natural high-molecular-weight polysaccharide, a purified extract from red seaweed. Different contents of biopolymers were used in the mix compositions, including 0.05 , 0.1 , and $0.15 \%$ (in weight of binder). The mix compositions are listed in Table 2.

\section{Production, Testing, and Cost Analysis}

During production, fly ash was mixed with fine aggregate, calcium hydroxide, milled waste glass, and biopolymer powder for $2 \mathrm{~min}$. Then, the alkali activator solution was added and mixed for $5 \mathrm{~min}$. Mortars were cast into cubic molds $\left(50 \times 50 \times 50 \mathrm{~mm}^{3}\right)$. After $24 \mathrm{~h}$, specimens were demolded and cured in four different curing conditions, including (1) curing at ambient temperature, (2) thermal curing at a temperature of $60^{\circ} \mathrm{C}$ for $1 \mathrm{~h},(3)$ thermal curing at a temperature of $60^{\circ} \mathrm{C}$ for $2 \mathrm{~h}$, and (4) thermal curing at a temperature of $60^{\circ} \mathrm{C}$ for $3 \mathrm{~h}$. After exposing the specimens to heat treatment, specimens were cured in laboratory conditions $\left(25^{\circ} \mathrm{C}\right.$ and $65 \%$ relative humidity). Compressive strength testing was carried out at 7 days with respect to the recommendations of the European standard EN1015-11 (CEN 1999). XRD analysis was employed to assess the crystalline structure of the mixtures. Powder XRD was implemented on a Bruker D8 Discover with $\mathrm{Cu}-\mathrm{K} \alpha$ radiation $(\lambda=154,060 \AA)$ at $40 \mathrm{kV}$ and $40 \mathrm{~mA}$. Each sample was scanned from 5 to $70^{\circ}$ at a speed of $0.4^{\circ} / \mathrm{s}$. The analysis for phase identification was performed using analytical software. Cost analysis of the mortars was carried out. The microstructural observation for several AACB mixtures was carried out using standard SEM microscopy (NOVA 200 Nano SEM). Micrographs and chemical compositions were collected at accelerating voltages of 10 and $15 \mathrm{kV}$, respectively, and variable working distance from 6 to 
Table 2. Mix Proportions of Geopolymer Mortars $\left(\mathrm{kg} / \mathrm{m}^{3}\right)$

\begin{tabular}{|c|c|c|c|c|c|c|c|c|c|}
\hline Mix composition & $\begin{array}{l}\text { Fly } \\
\text { ash }\end{array}$ & $\mathrm{CH}$ & MG & Xanthan & Carrageenan & Sand & SS & SH & $\begin{array}{r}\text { Molarity } \\
(\mathrm{mol} / \mathrm{L})\end{array}$ \\
\hline 90FA_10CH_4M_2SS/SH_0.8A/B & 379 & 42.0 & - & - & - & 1,685 & 269 & 134 & 4 \\
\hline 90FA_10CH_4M_1SS/SH_0.8A/B & 379 & 42.0 & - & & & 1,685 & 169 & 169 & \\
\hline 80FA_10CH_10MG_4M_2SS/SH_0.8A/B & 332 & 41.6 & 41.6 & & & 1,664 & 222 & 111 & \\
\hline 75FA_10CH_15MG_4M_1.5SS/SH_0.8A/B & 308 & 41.1 & 61.7 & & & 1,647 & 198 & 132 & \\
\hline 70FA_10CH_20MG_4M_1SS/SH_0.8A/B & 285 & 40.7 & 81.5 & & & 1,630 & 163 & 163 & \\
\hline 90FA_10CH_8M_2SS/SH_0.8A/B & 379 & 42.0 & - & & & 1,685 & 269 & 134 & 8 \\
\hline 90FA_10CH_8M_1SS/SH_0.8A/B & 379 & 42.0 & - & & & 1,685 & 169 & 169 & \\
\hline 80FA_10CH_10MG_8M_2SS/SH_0.8A/B & 332 & 41.6 & 41.6 & & & 1,664 & 222 & 111 & \\
\hline 75FA_10CH_15MG_8M_1.5SS/SH_0.8A/B & 309 & 41.1 & 61.7 & & & 1,647 & 198 & 132 & \\
\hline 70FA_10CH_20MG_8M_1SS/SH_0.8A/B & 285 & 40.7 & 81.5 & & & 1,630 & 163 & 163 & \\
\hline 90FA_10CH_4M_2SS/SH_0.8A/B_0.05CAR & 379 & 42.0 & - & & 0.210 & 1,685 & 269 & 134 & 4 \\
\hline 90FA_10CH_4M_1SS/SH_0.8A/B_0.05CAR & 379 & 42.0 & - & & 0.210 & 1,685 & 169 & 169 & \\
\hline 80FA_10CH_10MG_4M_2SS/SH_0.8A/B_0.05CAR & 332 & 41.6 & 41.6 & & 0.208 & 1,664 & 222 & 111 & \\
\hline 75FA_10CH_15MG_4M_1.5SS/SH_0.8A/B_0.05CAR & 308 & 41.1 & 61.7 & & 0.205 & 1,647 & 198 & 132 & \\
\hline 70FA_10CH_20MG_4M_1SS/SH_0.8A/B_0.05CAR & 285 & 40.7 & 81.5 & & 0.200 & 1,630 & 163 & 163 & \\
\hline 90FA_10CH_8M_2SS/SH_0.8A/B_0.05CAR & 379 & 42.0 & - & & 0.210 & 1,685 & 269 & 134 & 8 \\
\hline 90FA_10CH_8M_1SS/SH_0.8A/B_0.05CAR & 379 & 42.0 & - & & 0.210 & 1,685 & 169 & 169 & \\
\hline 80FA_10CH_10MG_8M_2SS/SH_0.8A/B_0.05CAR & 332 & 41.6 & 41.6 & & 0.208 & 1,664 & 222 & 111 & \\
\hline 75FA_10CH_15MG_8M_1.5SS/SH_0.8A/B_0.05CAR & 309 & 41.1 & 61.7 & & 0.205 & 1,647 & 198 & 132 & \\
\hline 70FA_10CH_20MG_8M_1SS/SH_0.8A/B_0.05CAR & 285 & 40.7 & 81.5 & & 0.200 & 1,630 & 163 & 163 & \\
\hline 90FA_10CH_4M_2SS/SH_0.8A/B_0.1CAR & 379 & 42.0 & - & - & 0.420 & 1,685 & 269 & 134 & 4 \\
\hline 90FA_10CH_4M_1SS/SH_0.8A/B_0.1CAR & 379 & 42.0 & - & & 0.420 & 1,685 & 169 & 169 & \\
\hline 80FA_10CH_10MG_4M_2SS/SH_0.8A/B_0.1CAR & 332 & 41.6 & 41.6 & & 0.410 & 1,664 & 222 & 111 & \\
\hline 75FA_10CH_15MG_4M_1.5SS/SH_0.8A/B_0.1CAR & 308 & 41.1 & 61.7 & & 0.410 & 1,647 & 198 & 132 & \\
\hline 70FA_10CH_20MG_4M_1SS/SH_0.8A/B_0.1CAR & 285 & 40.7 & 81.5 & & 0.400 & 1,630 & 163 & 163 & \\
\hline 90FA_10CH_8M_2SS/SH_0.8A/B_-0.1CAR & 379 & 42.0 & - & & 0.420 & 1,685 & 269 & 134 & 8 \\
\hline 90FA_10CH_8M_1SS/SH_0.8A/B_0.1CAR & 379 & 42.0 & - & & 0.420 & 1,685 & 169 & 169 & \\
\hline 80FA_10CH_10MG_8M_2SS/SH_0.8A/B_0.1CAR & 332 & 41.6 & 41.6 & & 0.410 & 1,664 & 222 & 111 & \\
\hline 75FA_10CH_15MG_8M_1.5SS/SH_0.8A/B_0.1CAR & 309 & 41.1 & 61.7 & & 0.410 & 1,647 & 198 & 132 & \\
\hline 70FA_10CH_20MG_8M_1SS/SH_0.8A/B_0.1CAR & 285 & 40.7 & 81.5 & & 0.400 & 1,630 & 163 & 163 & \\
\hline 90FA_10CH_4M_2SS/SH_0.8A/B_0.15CAR & 379 & 42.0 & - & - & 0.630 & 1,685 & 269 & 134 & 4 \\
\hline 90FA_10CH_4M_1SS/SH_0.8A/B_0.15CAR & 379 & 42.0 & - & & 0.630 & 1,685 & 169 & 169 & \\
\hline 80FA_10CH_10MG_4M_2SS/SH_0.8A/B_0.15CAR & 332 & 41.6 & 41.6 & & 0.624 & 1,664 & 222 & 111 & \\
\hline 75FA_10CH_15MG_4M_1.5SS/SH_0.8A/B_0.15CAR & 308 & 41.1 & 61.7 & & 0.617 & 1,647 & 198 & 132 & \\
\hline 70FA_10CH_20MG_4M_1SS/SH_0.8A/B_0.15CAR & 285 & 40.7 & 81.5 & & 0.611 & 1,630 & 163 & 163 & \\
\hline 90FA_10CH_8M_2SS/SH_0.8A/B_0.15CAR & 379 & 42.0 & - & & 0.630 & 1,685 & 269 & 134 & 8 \\
\hline 90FA_10CH_8M_1SS/SH_0.8A/B_0.15CAR & 379 & 42.0 & - & & 0.630 & 1,685 & 169 & 169 & \\
\hline 80FA_10CH_10MG_8M_2SS/SH_0.8A/B_0.15CAR & 332 & 41.6 & 41.6 & & 0.624 & 1,664 & 222 & 111 & \\
\hline 75FA_10CH_15MG_8M_1.5SS/SH_0.8A/B_0.15CAR & 309 & 41.1 & 61.7 & & 0.617 & 1,647 & 198 & 132 & \\
\hline 70FA_10CH_20MG_8M_1SS/SH_0.8A/B_0.15CAR & 285 & 40.7 & 81.5 & & 0.611 & 1,630 & 163 & 163 & \\
\hline 90FA_10CH_4M_2SS/SH_0.8A/B_0.05XAN & 379 & 42.0 & - & 0.210 & - & 1,685 & 269 & 134 & 4 \\
\hline 90FA_10CH_4M_1SS/SH_0.8A/B_0.05 XAN & 379 & 42.0 & - & 0.210 & & 1,685 & 169 & 169 & \\
\hline 80FA_10CH_10MG_4M_2SS/SH_0.8A/B_0.05 XAN & 332 & 41.6 & 41.6 & 0.208 & & 1,664 & 222 & 111 & \\
\hline 75FA_10CH_15MG_4M_1.5SS/SH_0.8A/B_0.05 XAN & 308 & 41.1 & 61.7 & 0.205 & & 1,647 & 198 & 132 & \\
\hline 70FA_10CH_20MG_4M_1SS/SH_0.8A/B_0.05 XAN & 285 & 40.7 & 81.5 & 0.200 & & 1,630 & 163 & 163 & \\
\hline 90FA_10CH_8M_2SS/SH_0.8A/B_0.05 XAN & 379 & 42.0 & - & 0.210 & & 1,685 & 269 & 134 & 8 \\
\hline 90FA_10CH_8M_1SS/SH_0.8A/B_0.05 XAN & 379 & 42.0 & - & 0.210 & & 1,685 & 169 & 169 & \\
\hline 80FA_10CH_10MG_8M_2SS/SH_0.8A/B_0.05 XAN & 332 & 41.6 & 41.6 & 0.208 & & 1,664 & 222 & 111 & \\
\hline 75FA_10CH_15MG_8M_1.5SS/SH_0.8A/B_0.05 XAN & 309 & 41.1 & 61.7 & 0.205 & & 1,647 & 198 & 132 & \\
\hline 70FA_10CH_20MG_8M_1SS/SH_0.8A/B_0.05 XAN & 285 & 40.7 & 81.5 & 0.200 & & 1,630 & 163 & 163 & \\
\hline 90FA_10CH_4M_2SS/SH_0.8A/B_0.1 XAN & 379 & 42.0 & - & 0.420 & - & 1,685 & 269 & 134 & 4 \\
\hline 90FA_10CH_4M_1SS/SH_0.8A/B_0.1 XAN & 379 & 42.0 & - & 0.420 & & 1,685 & 169 & 169 & \\
\hline 80FA_10CH_10MG_4M_2SS/SH_0.8A/B_0.1 XAN & 332 & 41.6 & 41.6 & 0.410 & & 1,664 & 222 & 111 & \\
\hline 75FA_10CH_15MG_4M_1.5SS/SH_0.8A/B_0.1 XAN & 308 & 41.1 & 61.7 & 0.410 & & 1,647 & 198 & 132 & \\
\hline 70FA_10CH_20MG_4M_1SS/SH_0.8A/B_0.1 XAN & 285 & 40.7 & 81.5 & 0.400 & & 1,630 & 163 & 163 & \\
\hline 90FA_10CH_8M_2SS/SH_0.8A/B_0.1 XAN & 379 & 42.0 & - & 0.420 & & 1,685 & 269 & 134 & 8 \\
\hline 90FA_10CH_8M_1SS/SH_0.8A/B_0.1 XAN & 379 & 42.0 & - & 0.420 & & 1,685 & 169 & 169 & \\
\hline 80FA_10CH_10MG_8M_2SS/SH_0.8A/B_0.1 XAN & 332 & 41.6 & 41.6 & 0.410 & & 1,664 & 222 & 111 & \\
\hline 75FA_10CH_15MG_8M_1.5SS/SH_0.8A/B_0.1 XAN & 309 & 41.1 & 61.7 & 0.410 & & 1,647 & 198 & 132 & \\
\hline 70FA_10CH_20MG_8M_1SS/SH_0.8A/B_0.1 XAN & 285 & 40.7 & 81.5 & 0.400 & & 1,630 & 163 & 163 & \\
\hline
\end{tabular}


Table 2. (Continued.)

\begin{tabular}{|c|c|c|c|c|c|c|c|c|c|}
\hline Mix composition & $\begin{array}{l}\text { Fly } \\
\text { ash }\end{array}$ & $\mathrm{CH}$ & MG & Xanthan & Carrageenan & Sand & SS & $\mathrm{SH}$ & $\begin{array}{r}\text { Molarity } \\
(\mathrm{mol} / \mathrm{L})\end{array}$ \\
\hline 90FA_10CH_4M_2SS/SH_0.8A/B_0.15 XAN & 379 & 42.0 & - & 0.630 & \multirow[t]{10}{*}{ - } & 1,685 & 269 & 134 & \multirow[t]{5}{*}{4} \\
\hline 90FA_10CH_4M_1SS/SH_0.8A/B_0.15 XAN & 379 & 42.0 & - & 0.630 & & 1,685 & 169 & 169 & \\
\hline 80FA_10CH_10MG_4M_2SS/SH_0.8A/B_0.15 XAN & 332 & 41.6 & 41.6 & 0.624 & & 1,664 & 222 & 111 & \\
\hline 75FA_10CH_15MG_4M_1.5SS/SH_0.8A/B_0.15 XAN & 308 & 41.1 & 61.7 & 0.617 & & 1,647 & 198 & 132 & \\
\hline 70FA_10CH_20MG_4M_1SS/SH_0.8A/B_0.15 XAN & 285 & 40.7 & 81.5 & 0.611 & & 1,630 & 163 & 163 & \\
\hline 90FA_10CH_8M_2SS/SH_0.8A/B_0.15 XAN & 379 & 42.0 & - & 0.630 & & 1,685 & 269 & 134 & \multirow[t]{5}{*}{8} \\
\hline 90FA_10CH_8M_1SS/SH_0.8A/B_0.15 XAN & 379 & 42.0 & - & 0.630 & & 1,685 & 169 & 169 & \\
\hline 80FA_10CH_10MG_8M_2SS/SH_0.8A/B_0.15 XAN & 332 & 41.6 & 41.6 & 0.624 & & 1,664 & 222 & 111 & \\
\hline 75FA_10CH_15MG_8M_1.5SS/SH_0.8A/B_0.15 XAN & 309 & 41.1 & 61.7 & 0.617 & & 1,647 & 198 & 132 & \\
\hline 70FA_10CH_20MG_8M_1SS/SH_0.8A/B_0.15 XAN & 285 & 40.7 & 81.5 & 0.611 & & 1,630 & 163 & 163 & \\
\hline
\end{tabular}

Note: $\mathrm{SH}=$ sodium hydroxide; $\mathrm{SS}=$ sodium silicate

Table 3. Costs of the Materials Used in the Geopolymer Mix Compositions and the Energy Used for Heating

\begin{tabular}{lc}
\hline Parameter (Euro/kg) & Value \\
\hline Aggregate & 0.02 \\
MG & 0.009 \\
CH & 0.30 \\
Fly ash & 0.03 \\
Sodium silicate & 0.29 \\
Sodium hydroxide & 0.85 \\
Thermal curing & 0.05 \\
Carrageenan & 105.00 \\
Xanthan & 84.00 \\
\hline
\end{tabular}

$8 \mathrm{~mm}$. The cylindrical subsamples from Zones 1 to 3 were coated with a $30-n m$ layer of gold-palladium (60\% gold and $40 \%$ palladium), and then the SEM/EDS examination for all the specimens was conducted. The costs of the materials that were used to calculate the cost of the mortars are listed in Table 3.

\section{Results and Discussion}

\section{Compressive Strength at Ambient Temperature}

The results of the compressive strength after 7 days curing of AACB mixtures at ambient temperature without biopolymers are shown in Fig. 3. The mixture 80FA_10CH_10MG_2SS/SH_0.8A/B

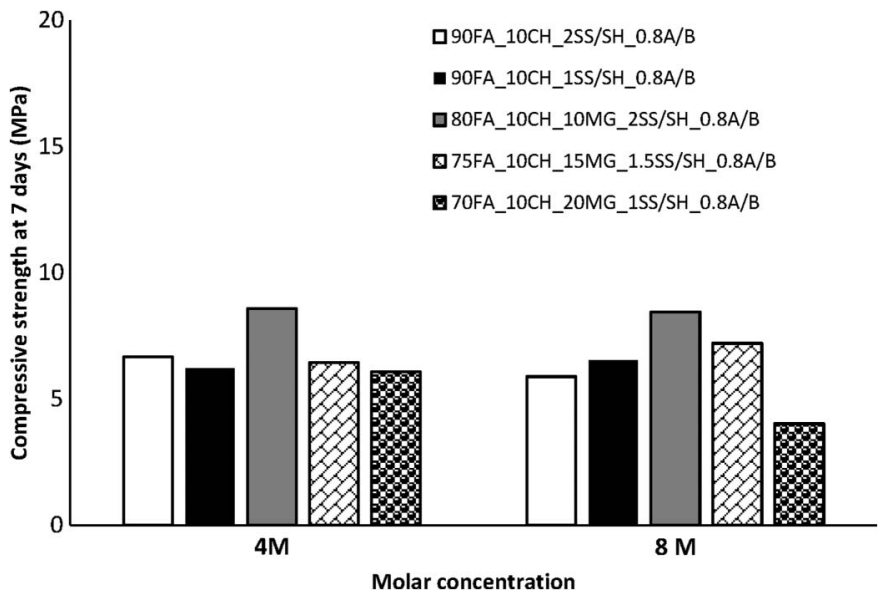

Fig. 3. Compressive strength of AACB mortars without biopolymers after 7 days of curing shows the highest compressive strength of around $9 \mathrm{MPa}$. This mechanical performance is high enough for several construction applications, such as use in renders and for masonry units, for both the $4 \mathrm{M}$ and $8 \mathrm{M}$ sodium hydroxide concentrations. The explanation lies in the fact that for low sodium hydroxide concentrations the main hydration product formed is a C-S-H gel (Alonso and Palomo 2001, 2001a; Garcia-Lodeiro et al. 2013, 2016). The replacement of $10 \%$ fly ash by milled waste glass shows a relevant increase in the short-term compressive strength of around $30 \%$. The waste glass provides reactive silica that contribute to the increase of the compressive strength. The reduction of the sodium silicate:sodium hydroxide ratio from 2 to 1 shows no influence on the compressive strength for both sodium hydroxide concentrations. Increasing the replacement of fly ash with milled glass from 10 to $20 \%$ by weight, as well as decreasing the ratio of sodium silicate to sodium hydroxide from 2 to 1 , reduced the compressive strength of the mix composition of 80FA_10CH_10MG_4M_2SS/SH_0.8A/B by about $30 \%$. This is because silica from waste glass is not as reactive as liquid $\mathrm{Na}_{2} \mathrm{SiO}_{3}$.

\section{Compressive Strength of Mixtures with Biopolymers Cured at Ambient Temperature}

Fig. 4 shows the compressive strength of AACB mixtures with the biopolymer carrageenan cured at ambient temperature over 7 days. The biopolymer carrageenan increased compressive strengths of mixtures 90FA_10CH_2SS/SH_0.8A/B and 90FA_10CH_1SS/ SH_0.8A/B. This increment was higher for these mixtures with $4 \mathrm{M}$ sodium hydroxide concentration. Because of the addition of carrageenan, the maximum compressive strength and the maximum increase of compressive strength were about $17 \mathrm{MPa}$ and 3 times, respectively, for the mixture 90FA_10CH_2SS/SH_0.8A/B with $0.15 \%$ of carrageenan. For mixtures 80FA_10CH_10MG_2SS/ SH_0.8A/B and 75FA_10CH_15MG_2SS/SH_0.8A/B with molar concentrations of $4 \mathrm{~mol} / \mathrm{L}$, the compressive strength increased by increasing the content of carrageenan up to $0.1 \%$, while increasing the content of carrageenan to $0.15 \%$ reduced the compressive strength. Conversely, by increasing the molar concentration from 4 to $8 \mathrm{~mol} / \mathrm{L}$, increasing the content of carrageenan up to $0.15 \%$ resulted in recording the maximum compressive strength (16.2 MPa for both mixtures 80FA_10CH_10MG_2SS/SH_0.8A/B and 75FA_10CH_15MG_1.5SS/SH_0.8A/B). As illustrated in Fig. 4(e), by increasing the replacement of fly ash with milled glass up to $20 \%$ by weight, as well as reducing the sodium silicate:sodium hydroxide ratio to 1 in the mix composition of 70FA_10CH_20MG_ 1SS/SH_0.8A/B, the rate of the compressive strength increment was slightly reduced. Moreover, increasing the molar concentration from 4 to $8 \mathrm{~mol} / \mathrm{L}$ has no significant effect on increasing the compressive 

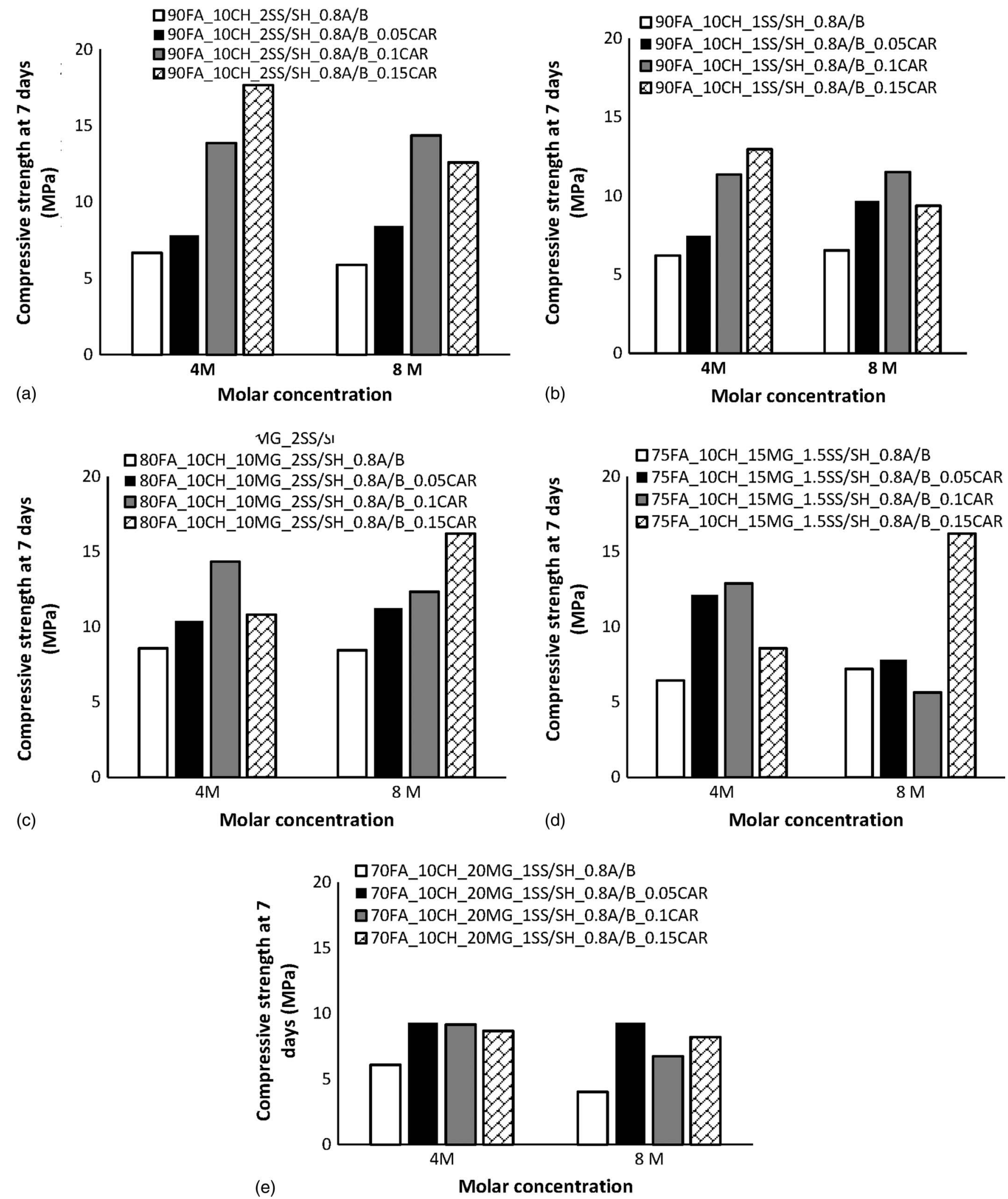

Fig. 4. Compressive strength of AACB mixtures with biopolymer carrageenan: (a) 90FA_10CH_2SS/SH_0.8 A/B; (b) 90FA_10CH_1SS/SH_0.8 A/B; (c) 80FA_10CH_10MG_2SS/SH_0.8 A/B; (d) 75FA_10CH_10MG_1.5SS/SH_0.8 A/B; (e) 70FA_10CH_20MG_1SS/SH_0.8 A/B

strength of the mix composition of 70FA_10CH_20MG_1SS/ SH_0.8A/B. Some authors who studied geopolymers with carrageenan have reported an increase in compressive strength with biopolymer content with a peak at $0.1 \%$ (Li and Zhang 2016).
This confirms that the use of $0.1 \%$ of carrageenan leads to optimum compressive strength. These authors suggested that the carrageenan coated and bridged the fly ash particles and led to the formation of a more condensed structure, improving the mechanical behavior of 


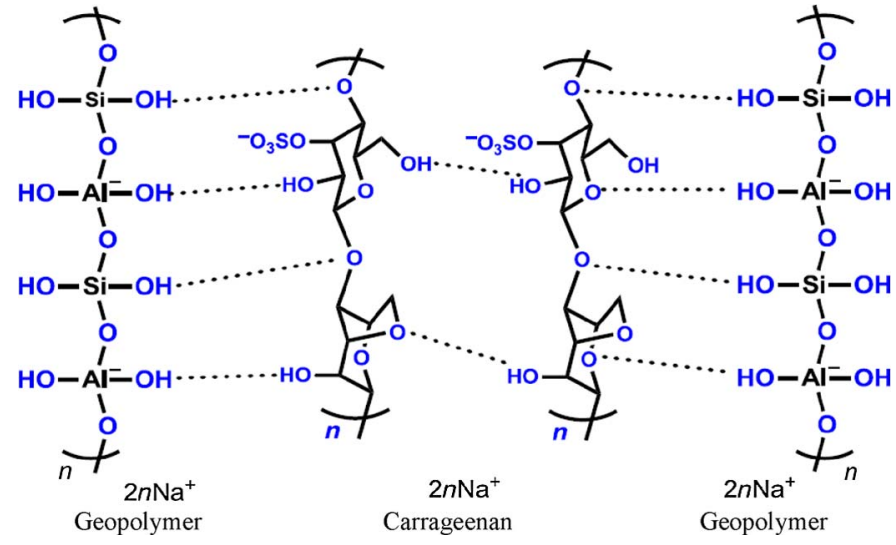

Fig. 5. Hydrogen bonds (represented by dashed lines) formed between carrageenan and fly ash-based geopolymer as well as within kappacarrageenan macromolecules (reprinted from Biopolymers and Biotech Admixtures for Eco-Efficient Construction Materials, Z. Li and L. Zhang, "Fly ash-based geopolymer with kappa-carrageenan biopolymer," pp. 173-192, Copyright 2016, with permission from Elsevier)

the biopolymer/geopolymer composite. For those authors, the primary effect of the incorporation of carrageenan into a geopolymer could be attributed to the presence of large amounts of hydrogen bonds in the biopolymer macromolecules (Fig. 5). Fig. 6 shows the compressive strength of AACB mixtures with biopolymer xanthan cured at ambient temperature over 7 days. Xanthan is not as effective as carrageenan at enhancing compressive strength. With the exception of 90FA_10CH_8M_1SS/SH_0.8A/B_0.1XAN, the addition of xanthan had no significant effect on increasing the compressive strength of mix compositions. The maximum compressive strength and increase of compressive strength as a result of the addition of xanthan were recorded to be about $13 \mathrm{MPa}$ and 2 times, respectively, for mixture 90FA_10CH_8M_1SS/SH_0.8A/ B_0.1XAN. Concerning the mixtures 80FA_10CH_10MG_2SS/ SH_0.8A/B, 75FA_10CH_15MG_1.5SS/SH_0.8A/B, and 70FA_ $10 \mathrm{CH}$ 20MG_1SS/SH_0.8A/B, the addition of xanthan biopolymer actually reduced their compressive strengths.

\section{Compressive Strength of Mixtures with Biopolymers and Precuring}

Fig. 7 shows the compressive strength of AACB mortars activated with $4 \mathrm{M}$ and with carrageenan using a precuring temperature of $60^{\circ} \mathrm{C}$ over several hours, while Fig. 8 shows the results for the same mixtures activated with an $8 \mathrm{M}$ sodium hydroxide concentration. Figs. 9 and 10 show the compressive strength of AACB mortars with xanthan. There is a general trend of strength increase with curing time. Several authors showed that precuring of alkali-activated binders before they are subjected to normal curing has been proven to further enhance their compressive strength (Kim and Kim 2013; Atis et al. 2015; Ming et al. 2016). Temperature helps to increase the dissolution of silica and aluminum from aluminosilicate precursors and accelerates the alkaline activation and the hardening process. However, some have reported a compressive strength loss (Redden and Neithalath 2014). On the other hand, this requires energy that is costly and has obvious environmental effects. Several temperatures and several exposure times were found for different mixtures and recently Gorhan et al. (2016) reported an ideal curing temperature and curing time of $60^{\circ} \mathrm{C}$ and $2 \mathrm{~h}$, respectively, for the production of the alkali-activated paste based on fly ash and metakaolin. For AACB mortars activated with $4 \mathrm{M}$ and with carrageenan biopolymer, the maximum compressive strength was $10.78 \mathrm{MPa}$ for the mixture 80FA $10 \mathrm{CH} 10 \mathrm{MG} 4 \mathrm{M} 2 \mathrm{SS} / \mathrm{SH} 0.8 \mathrm{~A} / \mathrm{B}$ exposed to $60^{\circ} \mathrm{C}$ for $3 \mathrm{~h}$, while the maximum increase of the compressive strength was detected to be about $43 \%$ for the mixture 75FA_10CH_15MG_4M_1.5SS/SH_0.8A/B with exposure to $3 \mathrm{~h}$ of thermal curing. A reduction in the compressive strength of mixtures 90FA_10CH_4M_2SS/SH_0.8A/B，90FA_10CH_4M_1SS/ SH_0.8A/B, and 80FA_10CH_10MG_4M_2SS/SH_0.8A/B was reported. A maximum compressive strength of $16.18 \mathrm{MPa}$ was obtained for mixture 75FA_10CH_15MG_4M_1.5SS/SH_0.8 A/B with the addition of $0.05 \%$ carrageenan and curing at $60^{\circ} \mathrm{C}$ for $3 \mathrm{~h}$, as depicted in Fig. 7(b). The maximum increase of compressive strength measured about $33 \%$ for $3 \mathrm{~h}$ of thermal curing in the mix composition of 75FA_10CH_15MG_4M_1.5SS/SH_0.8A/B, while the maximum reduction was detected to be about $14 \%$ with $1 \mathrm{~h}$ of thermal curing for the mix composition of 80FA_10CH_4M_ 2SS/SH_0.8A/B. Regarding the results indicated in Fig. 7(c), using the thermal curing had no significant effects on increasing the compressive strength of mixtures containing $0.1 \%$ carrageenan. The maximum increase and decrease of compressive strength as a result of thermal curing measured about 6 and $9 \%$ for mix compositions of 70FA_10CH_20MG_4M_1SS/SH_0.8A/B with $1 \mathrm{~h}$ of heating and 90FA_10CH_4M_1SS/SH_0.8A/B with $2 \mathrm{~h}$ of heating, respectively. Replacing $10 \%$ fly ash with milled glass (80FA_10CH_ 10MG_4M_2SS/SH_0.8A/B) slightly increased the compressive strength of the specimens heated up to $2 \mathrm{~h}$ at $60^{\circ} \mathrm{C}$, so that the maximum compressive strength was recorded to be $14.59 \mathrm{MPa}$ under $1 \mathrm{~h}$ of heating. With respect to the results illustrated in Fig. 7(d), thermal curing has no specific effect on increasing or decreasing the compressive strengths of the mix compositions containing $0.15 \%$ carrageenan. Use of thermal curing for the mixtures 90FA_10CH_ 4M_2SS/SH_0.8A/B_0.15CAR and 90FA_10CH_4M_1SS/SH_ $0.8 \mathrm{~A} / \mathrm{B} \_0.15 \mathrm{CAR}$ reduced the compressive strength in comparison to ambient temperature curing. The reduction of compressive strength in the mixture 90FA_10CH_4M_0.8A/B_0.15CAR was intensified by decreasing the ratio of sodium silicate to sodium hydroxide from 2 to 1 . Additionally, regardless of the curing time at $60^{\circ} \mathrm{C}$, it was obtained that replacing $10 \%$ fly ash with milled glass in the mix composition of 80FA_10CH_10MG_4M_2SS/ SH_0.8A/B reduced the compressive strength of the specimens, when compared to the mix composition of 90FA_10CH_4M_2SS/ SH $0.8 \mathrm{~A} / \mathrm{B}$. By increasing the replacement of fly ash with milled glass and also reducing the ratio of sodium silicate to sodium hydroxide, the compressive strength was reduced, while thermal curing increased the compressive strengths of these mix compositions compared to the compressive strengths of specimens cured at ambient temperature. The maximum increase and decrease of compressive strength were recorded to be about 41 and $11 \%$ in the mix compositions of 75FA_10CH_15MG_4M_1.5SS/SH_0.8A/ B_0.15CAR with $3 \mathrm{~h}$ of heating and 90FA_10CH_4M_2SS/ SH_0.8A/B_0.15CAR with $1 \mathrm{~h}$ of heating, respectively. The compressive strength of the mixture 90FA_10CH_8M_2SS/SH_0.8A/ $\mathrm{B}$ increased regardless of curing time. However, reducing the sodium silicate:sodium hydroxide ratio from 2 to 1 and exposing specimens to under $1 \mathrm{~h}$ of heating decreased the compressive strength of the mix composition of 90FA_10CH_1SS/SH_0.8A/B. Increasing the time of thermal curing from $1 \mathrm{~h}$ to 2 and $3 \mathrm{~h}$ for the mix composition of 90FA_10CH_8M_1SS/SH_0.8A/B increased the polymerization process and subsequently increased the compressive strength. Interestingly, it was found that replacing $10 \%$ fly ash with milled glass in the mix composition of 80FA_10CH_ 10MG_8M_2SS/SH_0.8A/B not only reduced the compressive strength for a precuring during $2 \mathrm{~h}$ and increased it for a longer procuring period. When increasing the replacement of fly ash with milled glass from 10 to $20 \%$ by weight and decreasing the ratio of 

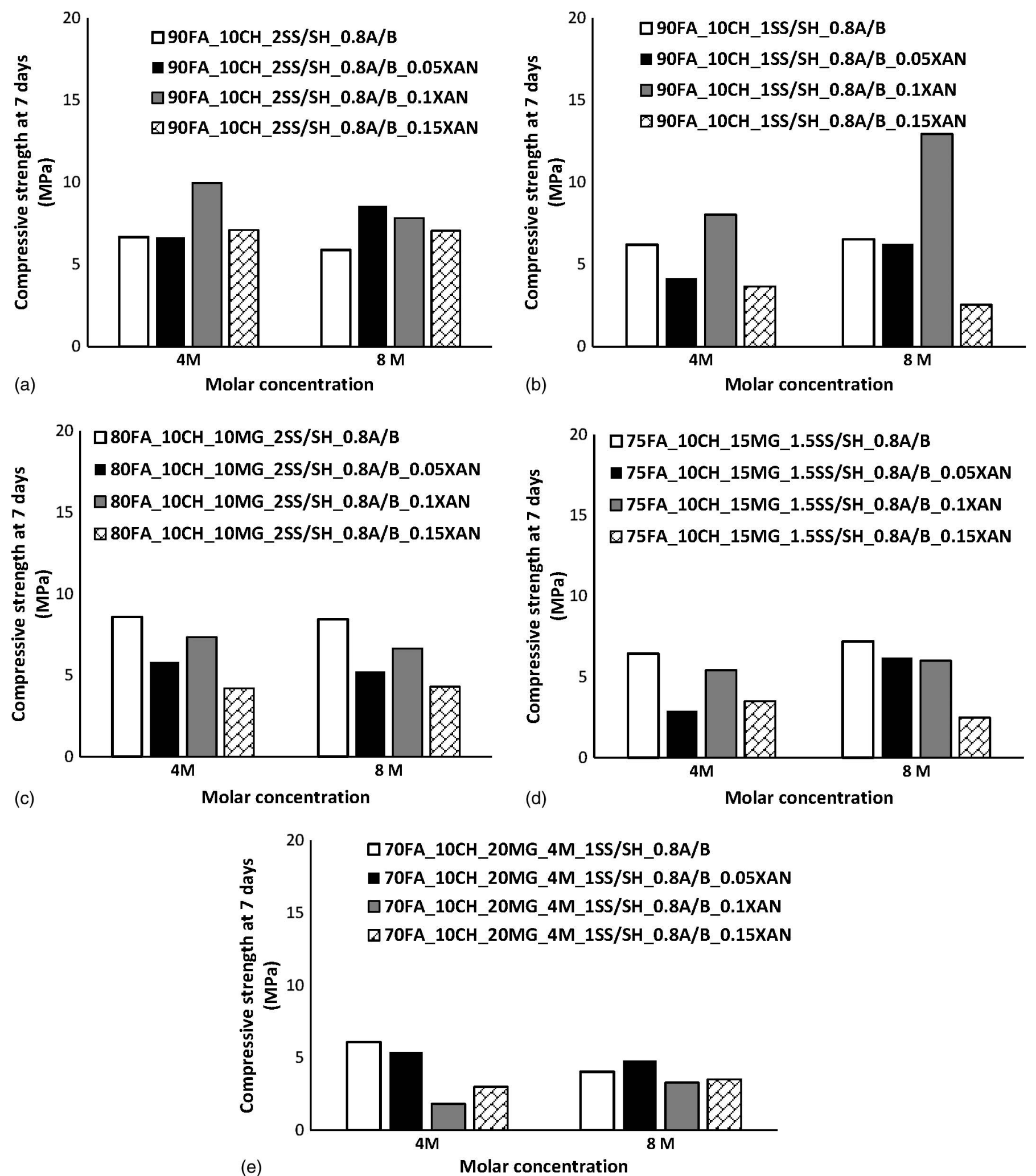

Fig. 6. Compressive strength of AACB mixtures with biopolymer xanthan: (a) 90FA_10CH_2SS/SH_0.8 A/B; (b) 90FA_10CH_1SS/SH_0.8 A/B; (c) 80FA_10CH_10MG_2SS/SH_0.8 A/B; (d) 75FA_10CH_10MG_1.5SS/SH_0.8 A/B; (e) 70FA_10CH_20MG_1SS/SH_0.8 A/B

sodium silicate to sodium hydroxide from 2 to 1 , compressive strength decreased. Because of thermal curing, the maximum increase in the compressive strength was recorded to be about $45 \%$ in the mix composition of 90FA_10CH_8M_2SS/SH_0.8A/B with $3 \mathrm{~h}$ of heating. The maximum increase of the compressive strength was detected for mixture 90FA_10CH_8M_2SS/SH_0.8A/B cured over $3 \mathrm{~h}$. Except for the mixture 75FA_10CH_15MG_8M_1.5SS/ SH_0.8A/B_0.05CAR, curing all mix compositions with $3 \mathrm{~h}$ of heating increased the compressive strength of specimens in comparison to curing at ambient temperature. Curing the mix composition of 75FA_10CH_15MG_8M_1.5SS/SH_0.8A/B_0.05CAR for $1 \mathrm{~h}$ increased the compressive strength, while heating longer 

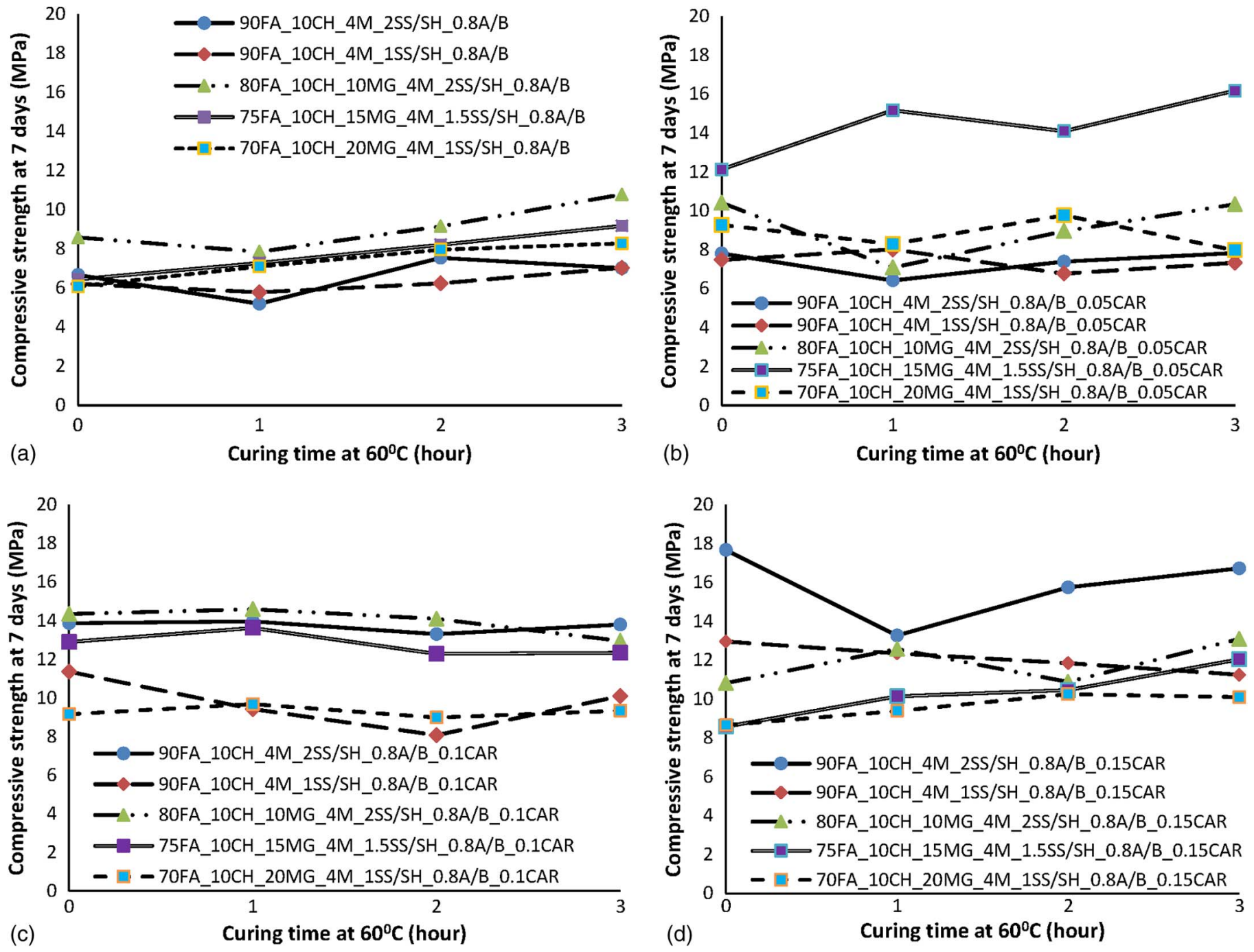

Fig. 7. Compressive strength of AACB mixtures cured at $60^{\circ} \mathrm{C}$ with $4 \mathrm{M}$ and the following biopolymer carrageenan content: (a) $0 \%$; (b) $0.05 \%$; (c) $0.1 \%$; (d) $0.15 \%$

than $1 \mathrm{~h}$ reduced the compressive strength. Figs. 8(c and d) show that an increased trend in the compressive strength of all compositions was obtained by increasing the content of carrageenan from 0.05 to 0.1 and $0.15 \%$ and increasing the curing time. Thus, the maximum compressive strength for mix compositions containing $0.1 \%$ carrageenan was obtained as $16 \mathrm{MPa}$ in the mix composition of 90FA_10CH_8M_2SS/SH_0.8A/B. Furthermore, the maximum increase of the compressive strength was recorded to be about $50 \%$ for the mix composition of 75FA_10CH_15MG_8M_1.5SS/ SH_0.8A/B_0.1CAR cured with $3 \mathrm{~h}$ of heating. As indicated in Fig. 8(d), by increasing the content of carrageenan from 0.1 to $0.15 \%$, the maximum compressive strength was obtained to be about $19.50 \mathrm{MPa}$ in the mix composition of 90FA_10CH_8M_ 2SS/SH_0.8A/B. Moreover, the maximum increase of the compressive strength was recorded to be about $62 \%$ for the mix composition of 90FA_10CH_8M_1SS/SH_0.8A/B_.015CAR, cured for $3 \mathrm{~h}$. Based on the results obtained in Fig. 9(a), heating all mix compositions at $60^{\circ} \mathrm{C}$ over $3 \mathrm{~h}$ increased the compressive strength, when compared to the mix compositions cured at ambient temperature. The maximum compressive strength was recorded to be about $9 \mathrm{MPa}$ for the mixture 70FA_10CH_20MG_4M_1SS/SH_0.8A/ B_0.05XAN with $2 \mathrm{~h}$ of heating. Additionally, the maximum increase of compressive strength was recorded to be more than two times in the mix composition of 75FA_10CH_15MG_4M_ $1.5 \mathrm{SS} / \mathrm{SH} \_0.8 \mathrm{~A} / \mathrm{B} \_0.05 \mathrm{XAN}$ as a result of $3 \mathrm{~h}$ of heating. When the content of xanthan is increased from 0.05 to $0.1 \%$ and $0.15 \%$, thermal curing had no significant effects on increasing the compressive strengths of mix compositions, as indicated in Figs. 9(b and c). The maximum increases of the compressive strength of mix compositions containing 0.1 and $0.15 \%$ xanthan were registered to be about 10 and $46 \%$ for the mix composition of 70FA_10CH_ 20MG_4M_1SS/SH_0.8A/B_0.1XAN cured with 1 and 3 h of heating, respectively. By comparing the results indicated in Figs. 9 and 10 , it was found that thermal curing results in the lower scattering compressive strengths in the mix compositions with molar concentrations of 4 than $8 \mathrm{~mol} / \mathrm{M} .3 \mathrm{~h}$ of heating increased the compressive strength of all mix compositions except for the mix composition of 70FA_10CH_20MG_8M_1SS/SH_0.8A/B_0.05XAN, as indicated in Fig. 10(a). Thermal curing not only increased the compressive strength for this mix composition, but also reduced it. The maximum compressive strength and the maximum increase of compressive strength were detected to be about $12.82 \mathrm{MPa}$ and $60 \%$ for mix compositions of 90FA_10CH_2SS/SH_0.8A/B_0.05XAN cured with $2 \mathrm{~h}$ of heating and 80FA_10CH_10MG_2SS/SH_0.8A/B_0.05XAN 

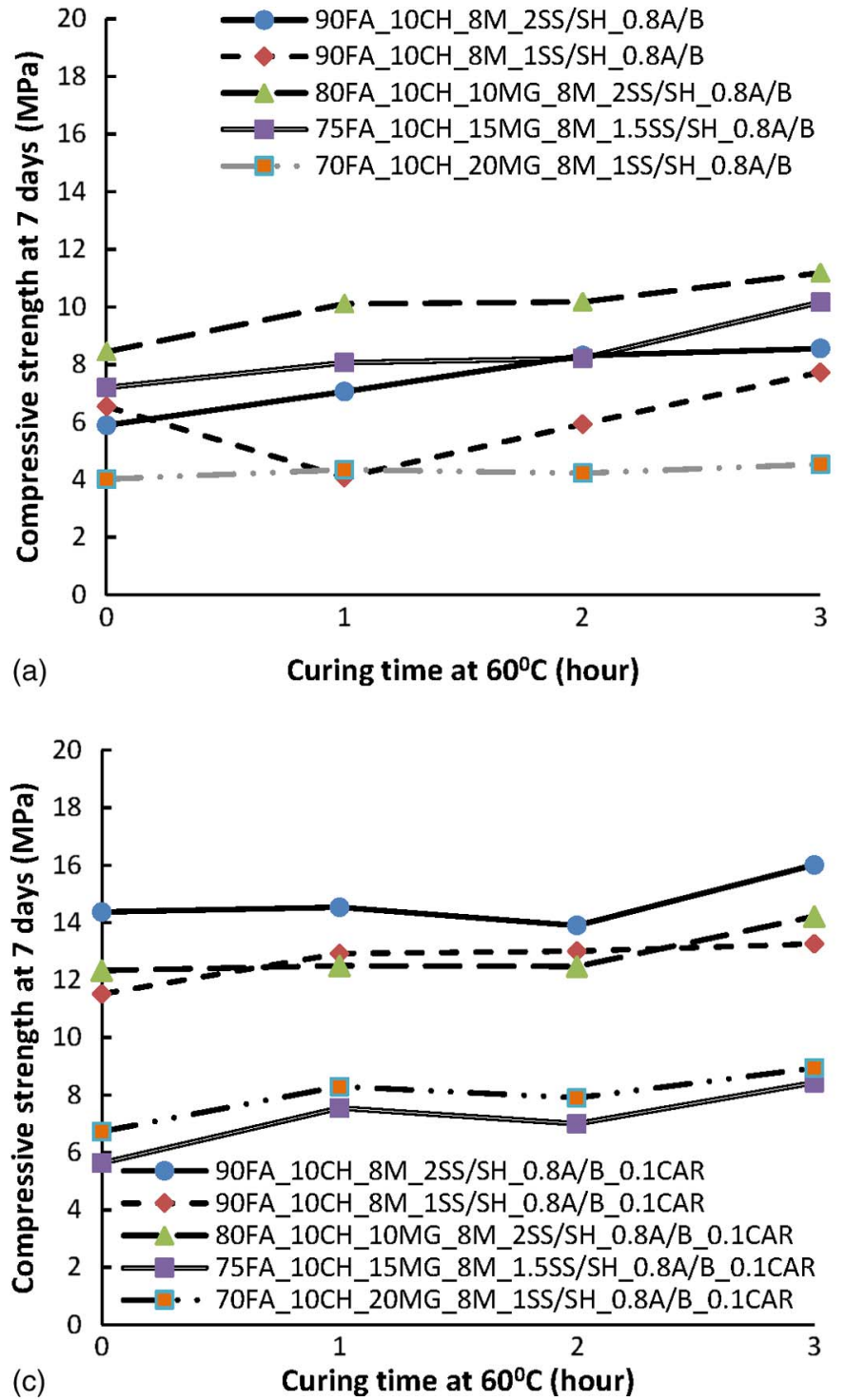
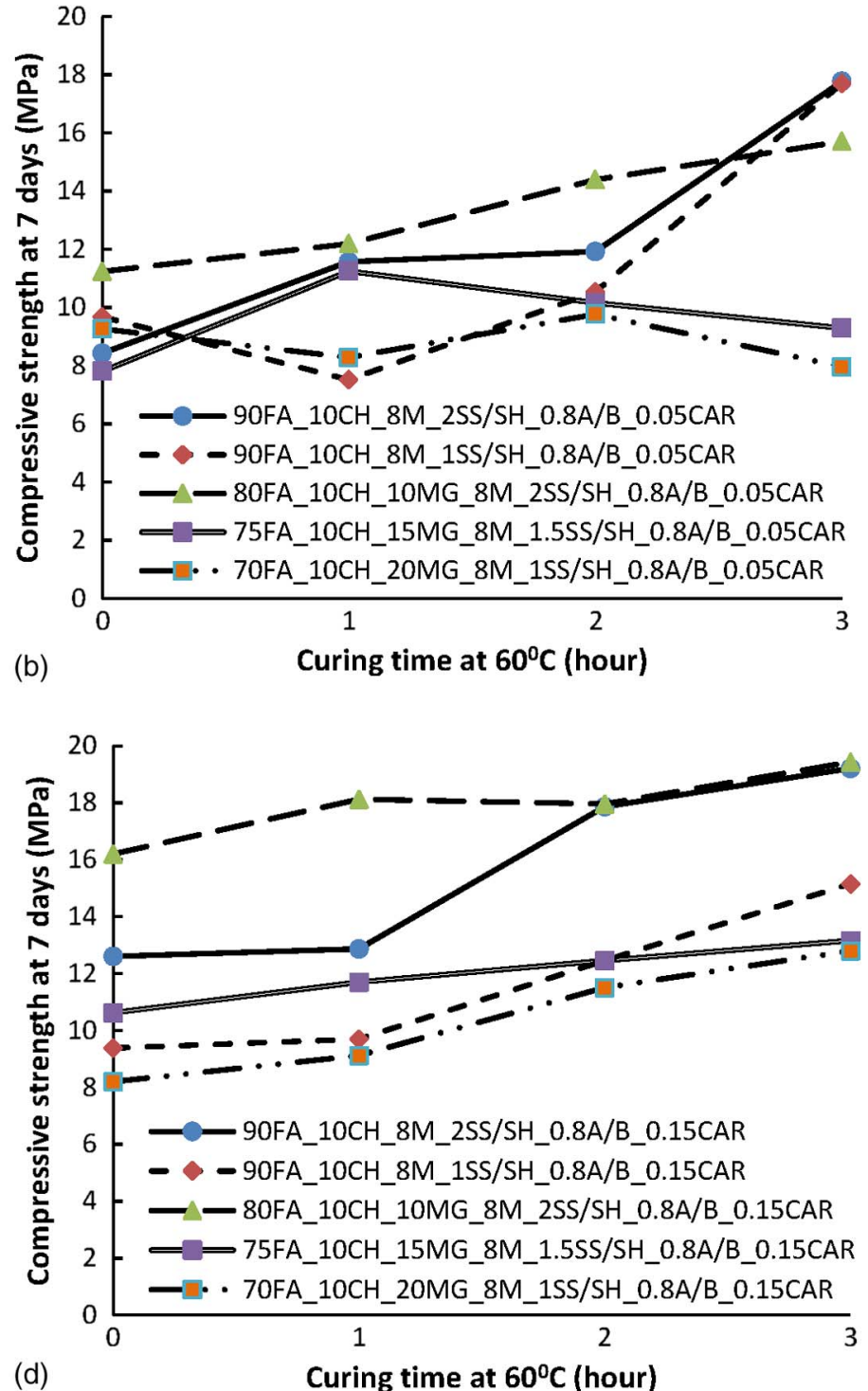

(d)

Fig. 8. Compressive strength of AACB mixtures cured at $60^{\circ} \mathrm{C}$ with $8 \mathrm{M}$ and to the following biopolymer carrageenan content: (a) $0 \%$; (b) $0.05 \%$; (c) $0.1 \%$; (d) $0.15 \%$

cured with $3 \mathrm{~h}$ of heating, respectively. Promisingly, replacing fly ash with milled glass from 10 to $15 \%$ by weight and reducing the sodium silicate:sodium hydroxide ratio from 2 to 1 did not decrease the compressive strength. By increasing the content of xanthan from 0.05 to $0.1 \%$, in Fig. 10(b), heating increased the compressive strengths of all mix compositions, except for 90FA_ 10CH_8M_1SS/SH_0.8A/B_0.1XAN. The maximum compressive strength and the maximum increase of compressive strength were recorded to be about $13 \mathrm{MPa}$ and $45 \%$ for mix compositions of 90FA_10CH_1SS/SH_0.8A/B_0.1XAN cured at ambient temperature and 80FA_10CH_10MG_8M_2SS/SH_0.8A/B_0.1XAN cured with $3 \mathrm{~h}$ of heating. Furthermore, it was interestingly observed that heating the specimens made with 80FA_10CH_10MG_8M_ 2SS/SH_0.8A/B_0.1XAN for more than a couple of hours caused the chemical reactions to become more rapid and subsequently enhanced the compressive strength, when compared to 90FA_10CH_ 8M_1SS/SH_0.8A/B_0.1XAN. The results in Fig. 10(c) indicate that thermal curing has no significant effects on increasing the compressive strength of all mix compositions containing $0.15 \%$ xanthan.
The maximum increase of the compressive strength was obtained to be about $45 \%$ for the mix composition of $80 \mathrm{FA} \_10 \mathrm{CH} \_10 \mathrm{MG}$ 8M_2SS/SH_0.8A/B_0.15XAN cured with $2 \mathrm{~h}$ of heating.

\section{SEM and XRD}

Fig. 11 shows the microstructure of two AACB mortars with the biopolymer carrageenan at room temperature and after $3 \mathrm{~h}$ at $60^{\circ} \mathrm{C}$. Figs. 11( $\mathrm{a}$ and $\mathrm{b})$ are related to an $\mathrm{AACB}$ mortar mixture that showed no strength increase after thermal treatment. The explanation for that may be related to the microcracks shown in Fig. 11(b). The second mixture showed around a $45 \%$ strength increase after being exposed to $60^{\circ} \mathrm{C}$ over $3 \mathrm{~h}$. The microstructure seems to confirm that because it appears to be denser. Fig. 12 shows XRD spectra of several AACB mortars. The C-(A)-S-H phase displays some structural similarity with aluminum-containing tobermorite (PDF\#19-0052). Portlandite $\left[\mathrm{Ca}(\mathrm{OH})_{2}\right]$ (PDF \#44-1481) and ettringite $\left[\mathrm{Ca}_{6} \mathrm{Al}_{2}(\mathrm{SO} 4)_{3}(\mathrm{OH})_{12} \cdot 26 \mathrm{H}_{2} \mathrm{O}\right](\mathrm{PDF} 441-1451)$ are also noticed. Small amounts of stilbite- $\mathrm{Ca}\left(\mathrm{NaCa}_{2} \mathrm{Al}_{5} \mathrm{Si}_{13} \mathrm{O}_{36} \cdot 14 \mathrm{H}_{2} \mathrm{O}\right)$ 

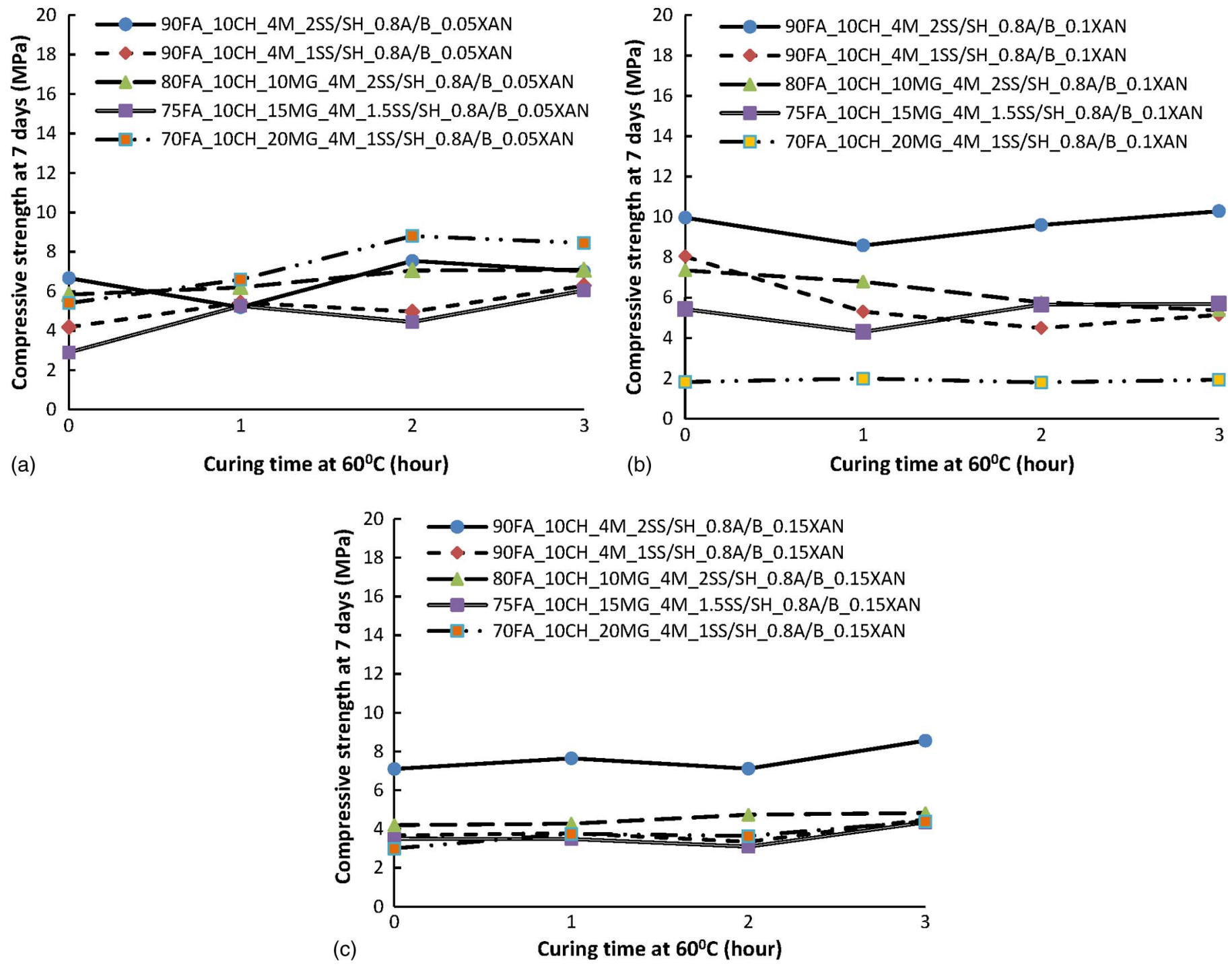

Fig. 9. Compressive strength of AACB mixtures cured at $60^{\circ} \mathrm{C}$ with $4 \mathrm{M}$ and the following biopolymer xanthan content: (a) $0 \%$; (b) $0.05 \%$; (c) $0.1 \%$; (d) $0.15 \%$

(PDF\#44-1479) were detected. Vaterite (PDF\#33-0268) is also present in AACB mortars.

\section{Cost Analysis}

Fig. 13 presents the cost of AACB mortars for different curing conditions. The minimum cost is around $150 \mathrm{Euro} / \mathrm{m}^{3}$ for the mixture 70FA_10CH_20MG_4M_1SS/SH_0.8 A/B, without the presence of biopolymers and with no temperature curing, while the maximum cost was recorded to be about $350 \mathrm{Euro} / \mathrm{m}^{3}$ for the mixture composition of 90FA_10CH_8M_2SS/SH_0.8 A/B. An increase in the sodium silicate content and sodium hydroxide concentration is responsible for an increase in the cost of AACB mortars. The minimum cost of mix compositions with the presence of biopolymers was about 200 Euro $/ \mathrm{m}^{3}$ for mixture 70FA_10CH_20MG_4M_ 1SS/SH_0.8 A/B_0.05CAR, while the maximum cost of the mix composition was detected to be about $400 \mathrm{Euro} / \mathrm{m}^{3}$ in $90 \mathrm{FA}$ $10 \mathrm{CH}$ _8M_2SS/SH_0.8 A/B_0.15CAR. Although thermal curing increased the chemical reactions and the compressive strength of AACB mortars, it is also responsible for a relevant cost increase.
Fig. 13(b) depicts the costs of mixtures cured with $1 \mathrm{~h}$ of heating. The minimum cost was $230 \mathrm{Euro} / \mathrm{m}^{3}$ for mixture 70FA_10CH_ 20MG_4M_1SS/SH_0.8 A. However, 260 Euro $/ \mathrm{m}^{3}$ is the minimum cost when $0.05 \%$ of the biopolymer carrageenan was used for the same mixture. The costs of mixtures cured with 2 and $3 \mathrm{~h}$ of heating are indicated in Figs. 13(c and d). They show an increase for all mixtures but with the same trend already noticed. Fig. 14(a) presents the cost of AACB mortars with different xanthan and for different curing conditions. The minimum cost was recorded to be about 200 Euro $/ \mathrm{m}^{3}$ for mixture 70FA_10CH_20MG_4M_1SS/ SH_0.8 A/B with $0.05 \%$ xanthan cured at ambient temperature. This cost was about $10 \%$ higher than this mix composition without the presence of xanthan. By increasing the curing time, as Fig. 14(c) shows, the cost suffers an increase of around $25 \%$. Fig. 14(d) shows that the minimum cost was about 340 Euro $/ \mathrm{m}^{3}$ for the mix composition of 70FA_10CH_20MG_4M_1SS/SH_ $0.8 \mathrm{~A} / \mathrm{B}$ containing $0.05 \%$ xanthan and cured with $3 \mathrm{~h}$ of heating. Additionally, the maximum cost in the mix compositions containing xanthan powder was obtained to be about $530 \mathrm{Euro} / \mathrm{m}^{3}$ for the mix composition of 90FA_10CH_8M_2SS/SH_0.8 A/B_0.15XAN cured with $3 \mathrm{~h}$ of heating. Abdollahnejad et al. (2015) studied 

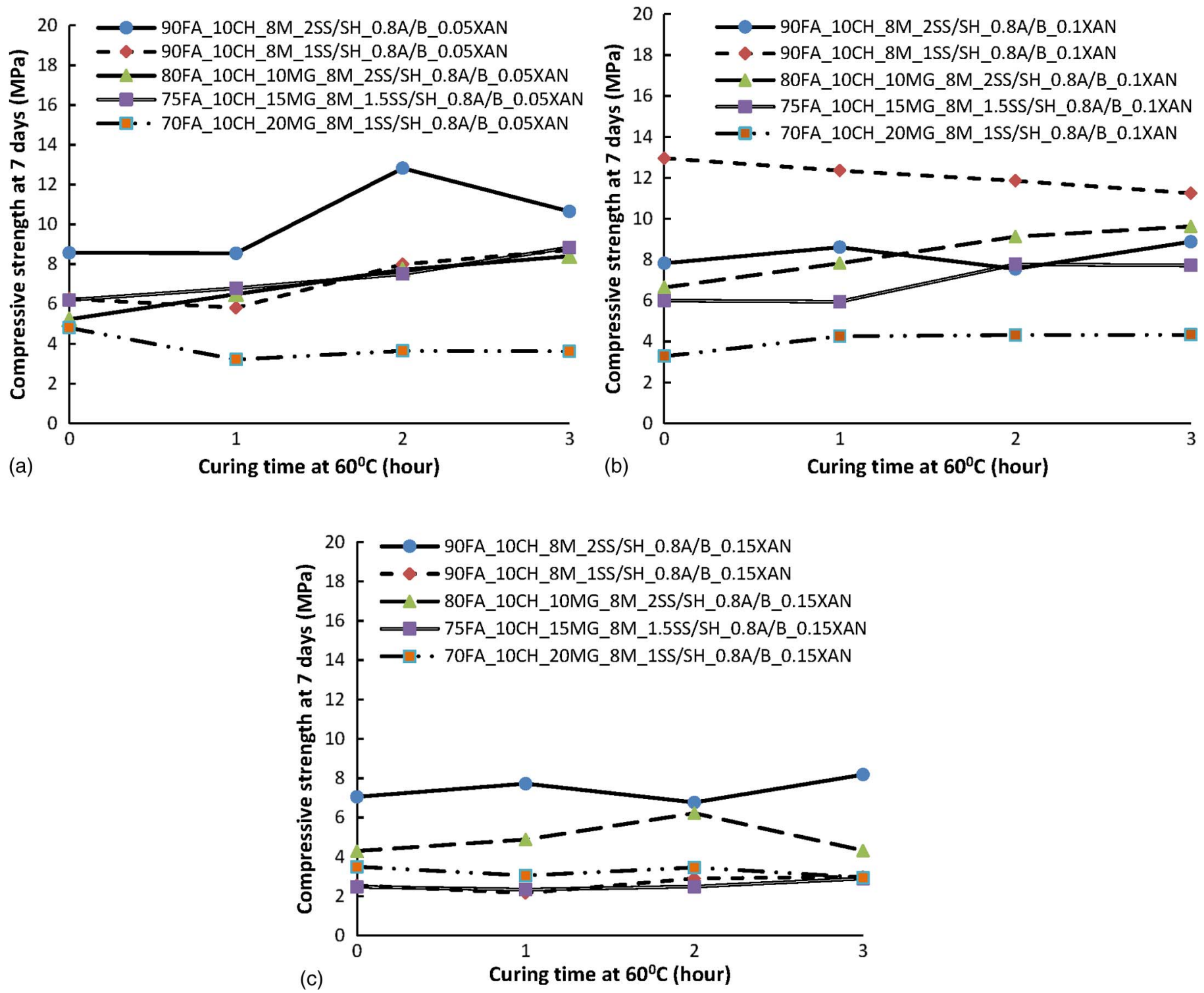

Fig. 10. Compressive strength of AACB mixtures cured at $60^{\circ} \mathrm{C}$ with $8 \mathrm{M}$ and to the following biopolymer xanthan content: (a) $0 \%$; (b) $0.05 \%$; (c) $0.1 \%$; (d) $0.15 \%$

alkali-activated mortars with higher costs between 300 and 600 Euro $/ \mathrm{m}^{3}$. Such high costs were the result of a higher sodium silicate content and a higher sodium hydroxide concentration. However, the same authors found an optimum cost of 67 Euro $/ \mathrm{m}^{3}$ for one-part alkali-activated mortars (Abdollahnejad et al. 2016). This means that AACB mortars still need further investigation in order to become cost-efficient enough.

\section{Conclusions}

The results of the present investigations are as follows. The results show that a mixture of $80 \%$ fly ash, $10 \%$ waste glass, and $10 \%$ calcium hydroxide activated with an alkaline activator based on a $4 \mathrm{M}$ sodium hydroxide solution show the highest compressive strength. The reduction of the sodium silicate content is associated with a reduction of compressive strength that is slightly compensated by the replacement of fly ash with waste glass. The mixtures containing carrageenan show better workability compared to mix compositions containing xanthan. The results show that an increase in biopolymer carrageenan content is associated with an increase in compressive strength and that the use of $0.1 \%$ carrageenan leads to optimum compressive strength. The use of xanthan shows no beneficial effects on the compressive strength of AACB mortars. Several mixtures with xanthan even show a reduction in compressive strength. Thermal curing shows a relevant increase in the compressive strength of AACB mortars. The minimum cost is 160 Euro $/ \mathrm{m}^{3}$ for the mixture 70FA_10CH_20MG_4M_1SS/ SH_0.8 A/B, without the presence of biopolymers, while the maximum cost was recorded to be about 350 Euro $/ \mathrm{m}^{3}$ in the mix composition of 90FA_10CH_8M_2SS/SH_0.8 A/B. The use of biopolymers also represents a substantial increase in the cost of the mortars, since the use of the biopolymer carrageenan is associated with the highest cost of around 400 Euro $/ \mathrm{m}^{3}$. Increases in the sodium silicate content and sodium hydroxide concentration are responsible for an increase in the cost of AACB mortars. Curing with temperature also contributes to a relevant increase in the cost of AACB mortars. 

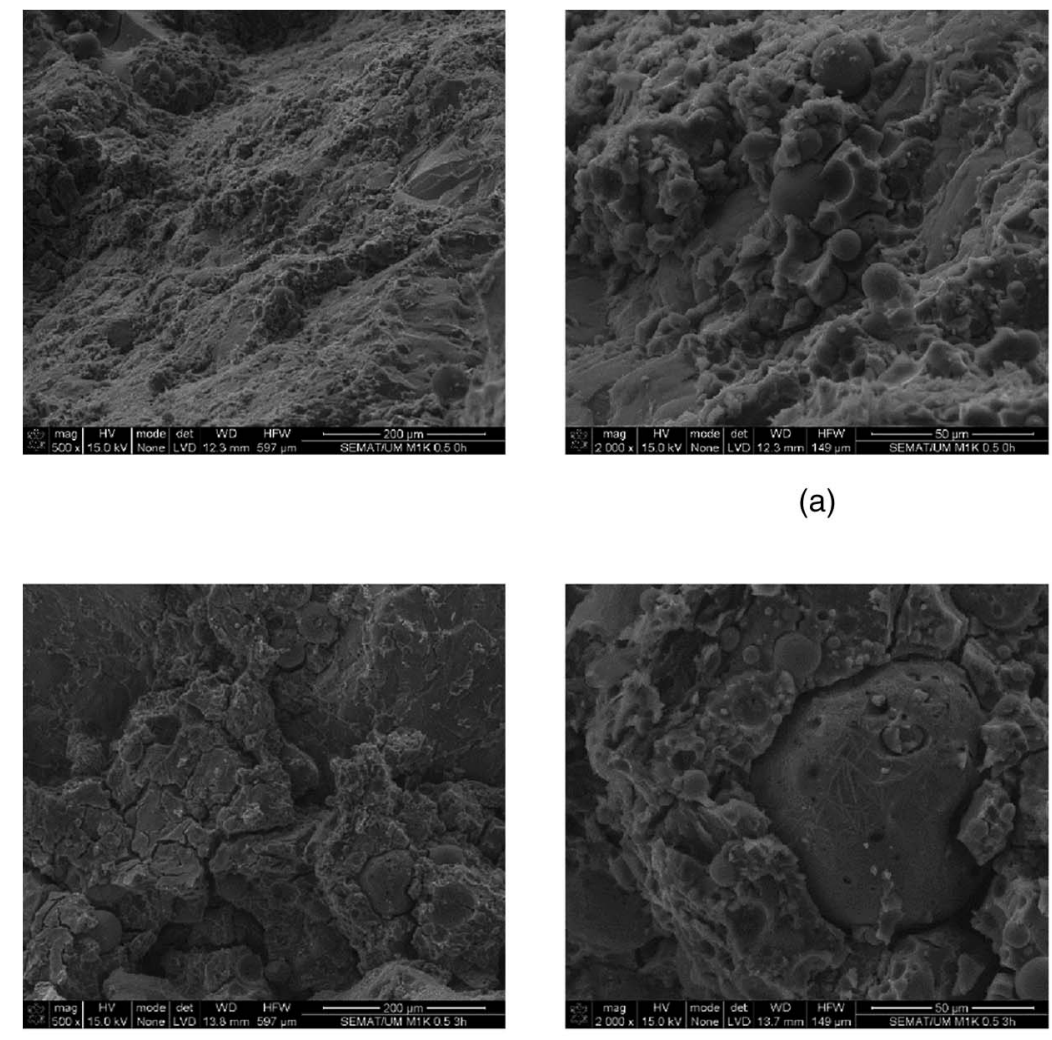

(b)
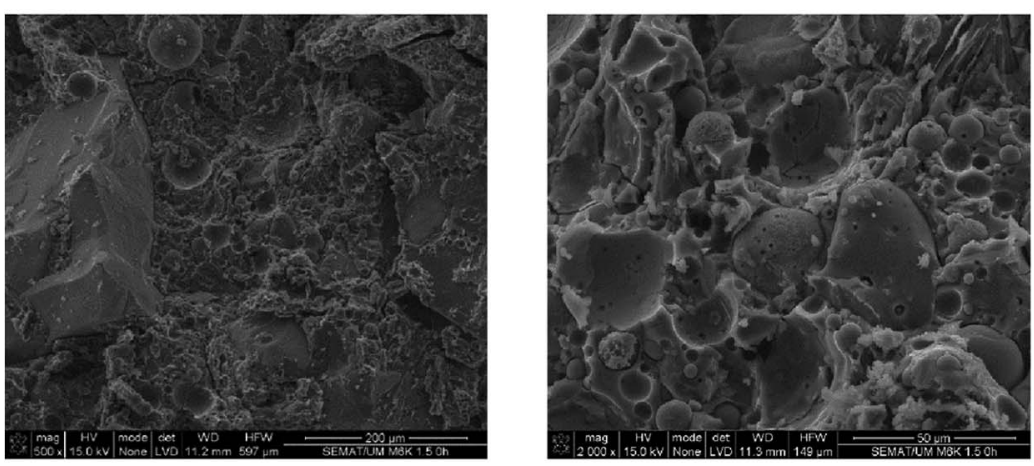

(c)
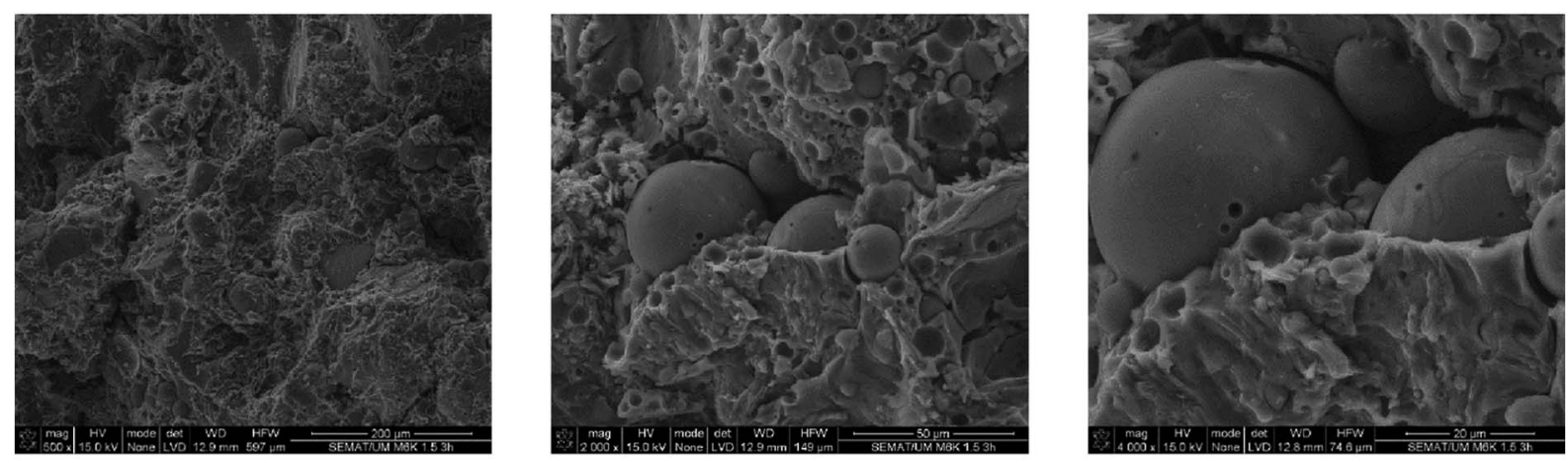

(d)
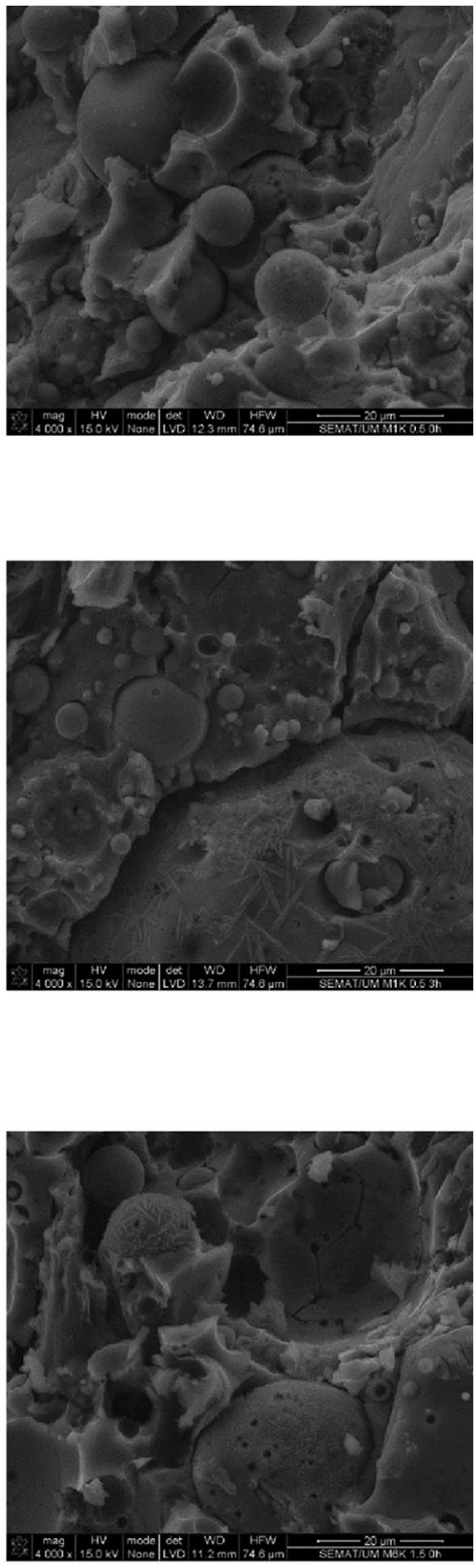

(a)

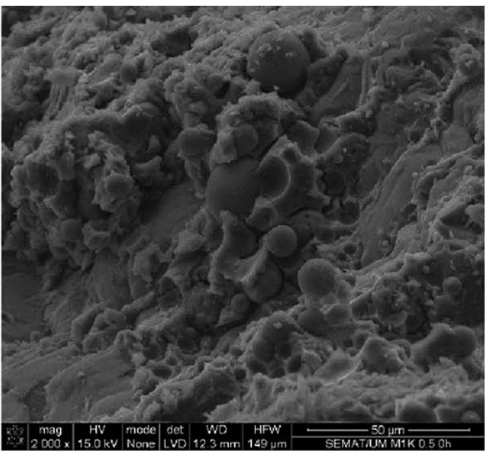


(a)

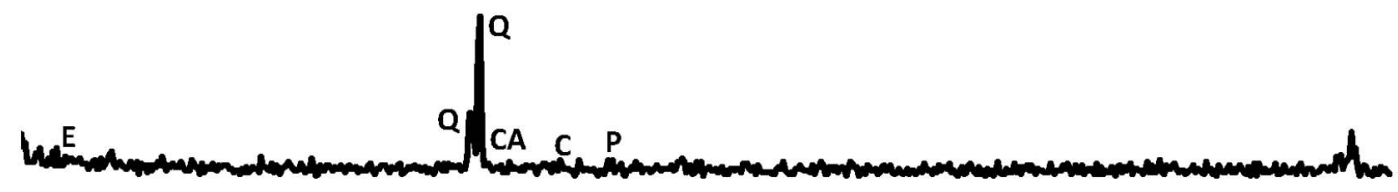

(b)

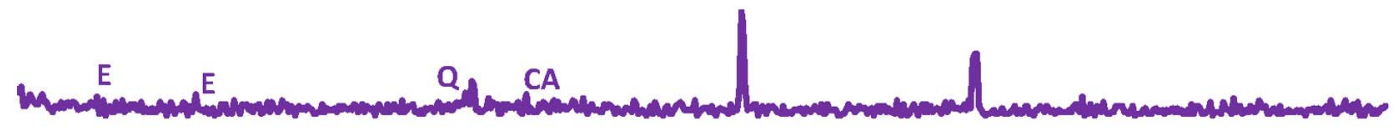

(c)

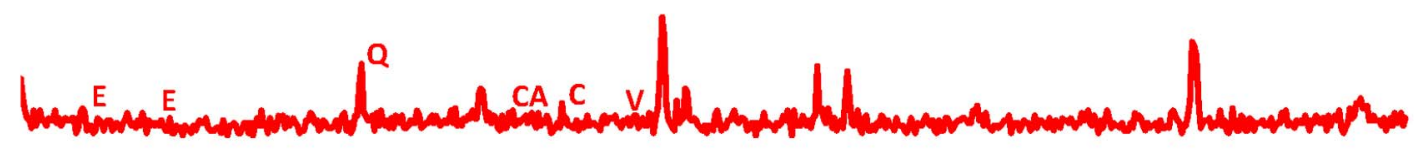

(d)

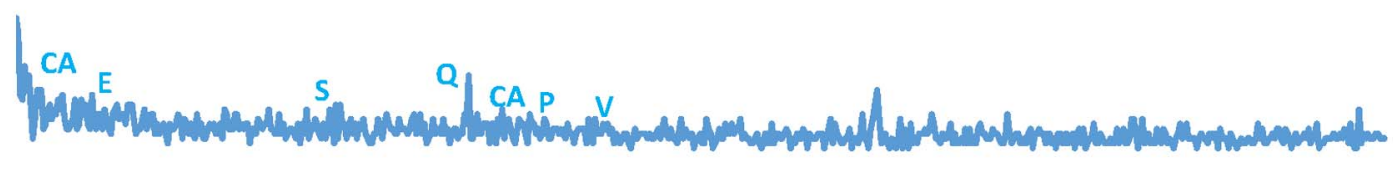

(e)

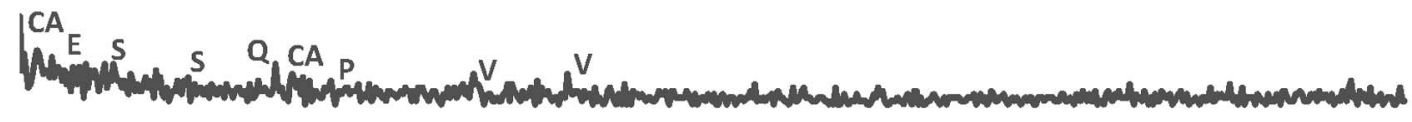

(f)

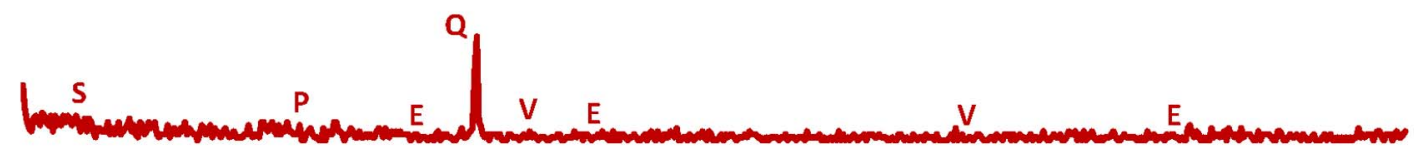

(g)

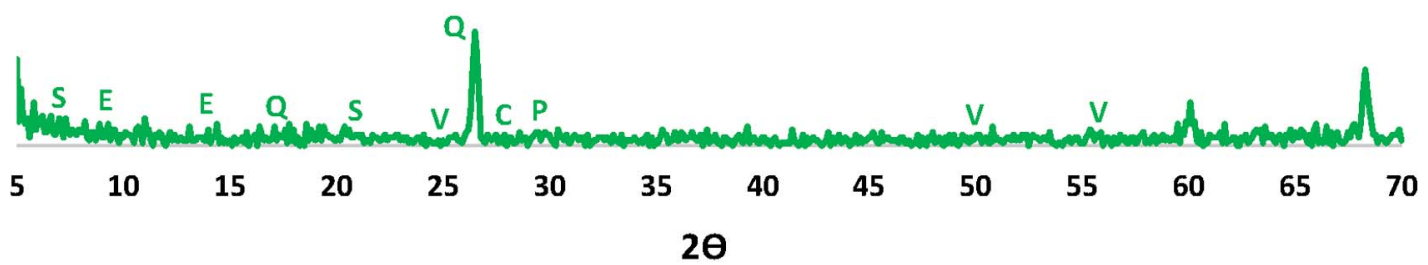

Fig. 12. XRD results for the mix composition of (a) 90FA_10CH_4M_2SS/SH_0.8 A/B_0.15CAR cured at 60 ${ }^{\circ} \mathrm{C}$ for $3 \mathrm{~h}$; (b) 90FA_10CH_4M_1SS/ SH_0.8 A/B_0.1CAR cured at ambient temperature; (c) 90FA_10CH_4M_1SS/SH_0.8 A/B_0.1CAR cured at 60 ${ }^{\circ} \mathrm{C}$ for 2 h; (d) 90FA_10CH_8M_2SS/SH_0.8 A/B_0.05CAR cured at $60^{\circ} \mathrm{C}$ for $1 \mathrm{~h}$; (e) $90 \mathrm{FA} \_10 \mathrm{CH} \_8 \mathrm{M} \_2 \mathrm{SS} / \mathrm{SH} \_0.8$ A/B_0.05CAR cured at 60 ${ }^{\circ} \mathrm{C}$ for $3 \mathrm{~h}$; (f) 90FA_10CH_8M_2SS/SH_0.8 A/B_0.15CAR cured at ambient temperature; (g) 90FA_10CH_8M_2SS/SH_0.8 A/B_0.15CAR cured at $60^{\circ} \mathrm{C}$ for $3 \mathrm{~h}$ (Q-Quartz, E-Ettringite, P-Portlandite, CA-Calcium Aluminate, C-Calcite, V-Vaterite, S-Stilbite) 


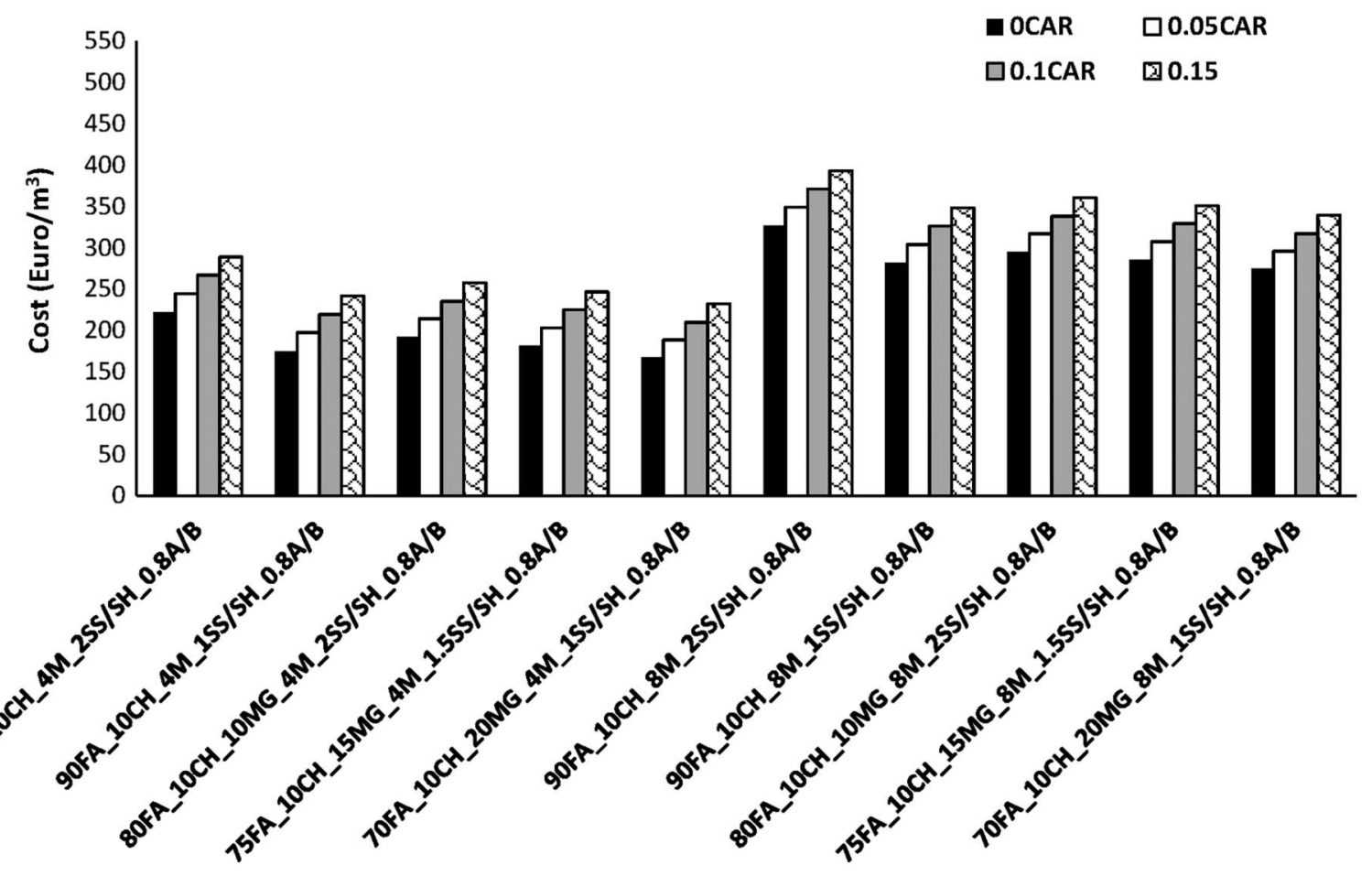

(a)

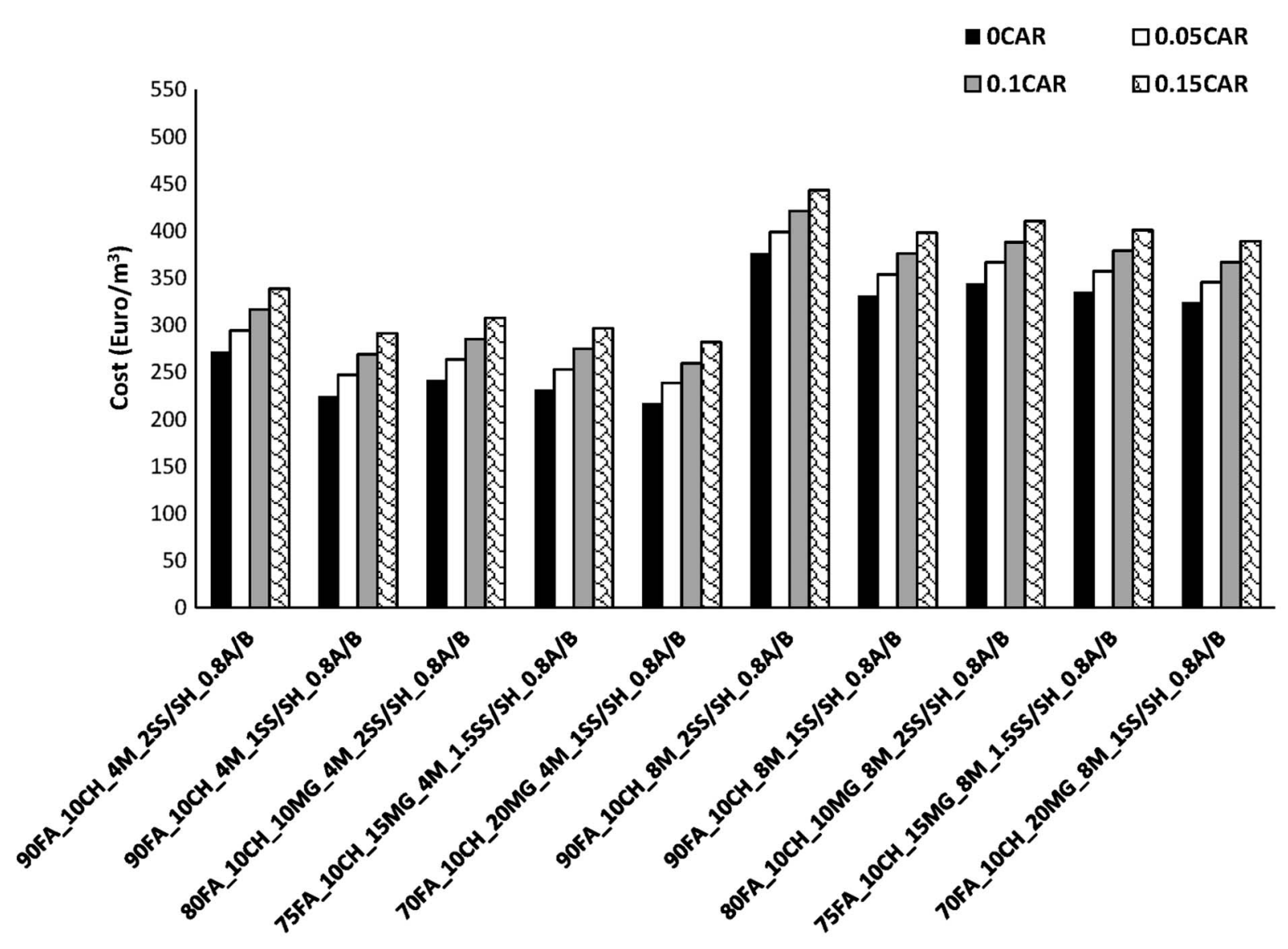

(b)

Fig. 13. Cost of AACB mortars with different carrageenan content and cured (a) at ambient temperature; (b) with $1 \mathrm{~h}$ of heating; (c) with $2 \mathrm{~h}$ of heating; (d) with $3 \mathrm{~h}$ of heating 


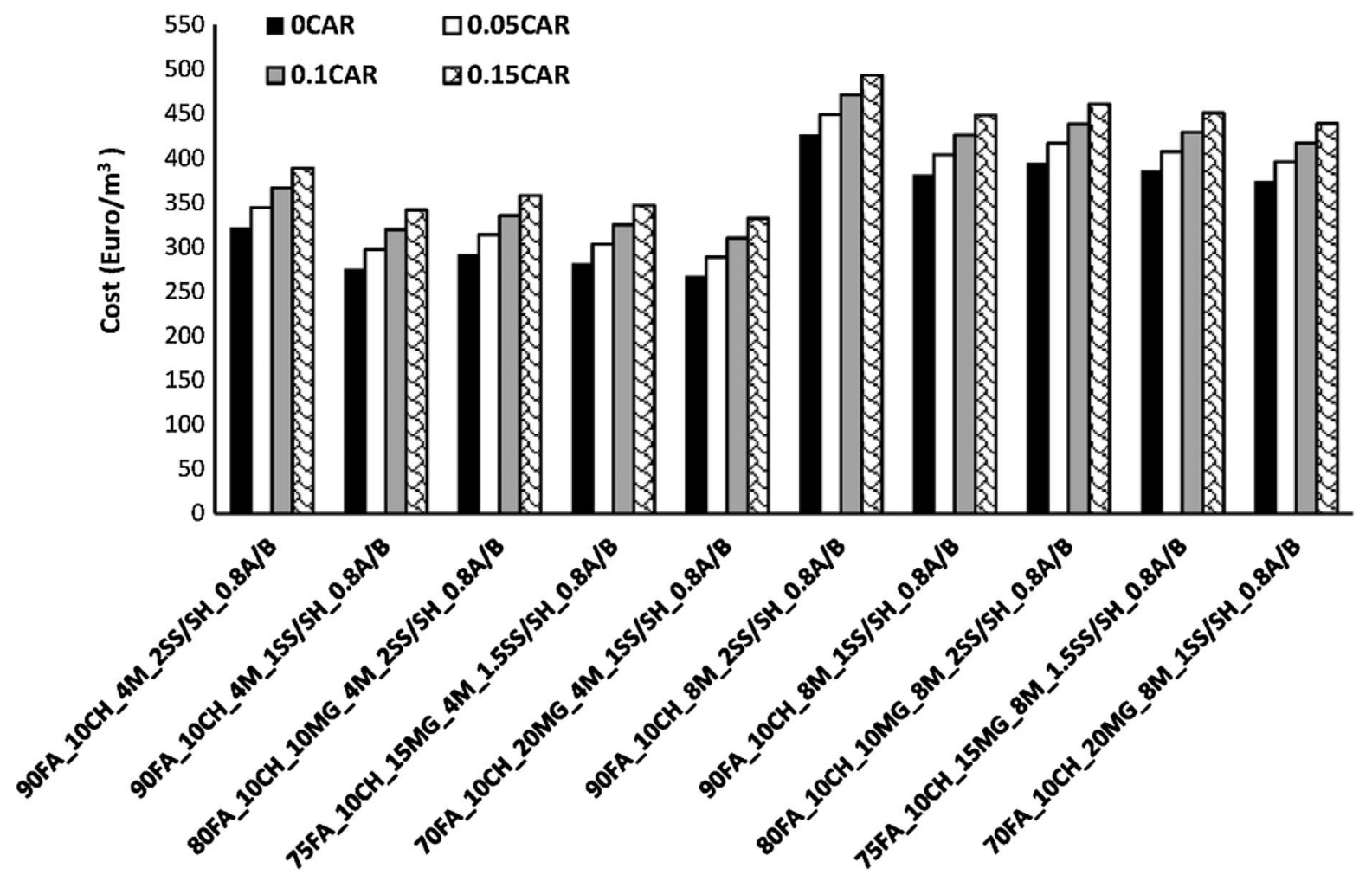

(c)

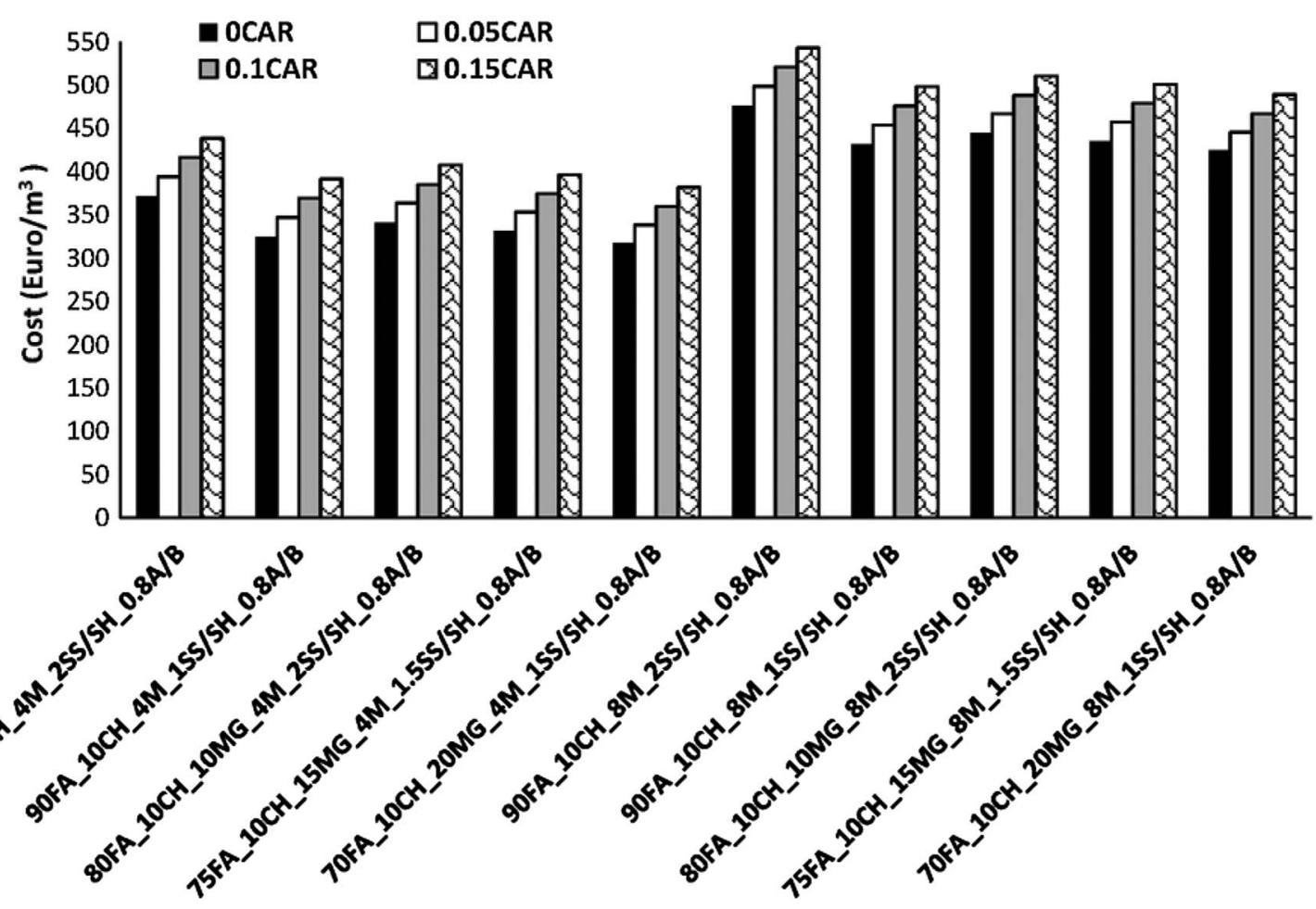

(d)

Fig. 13. (Continued.) 


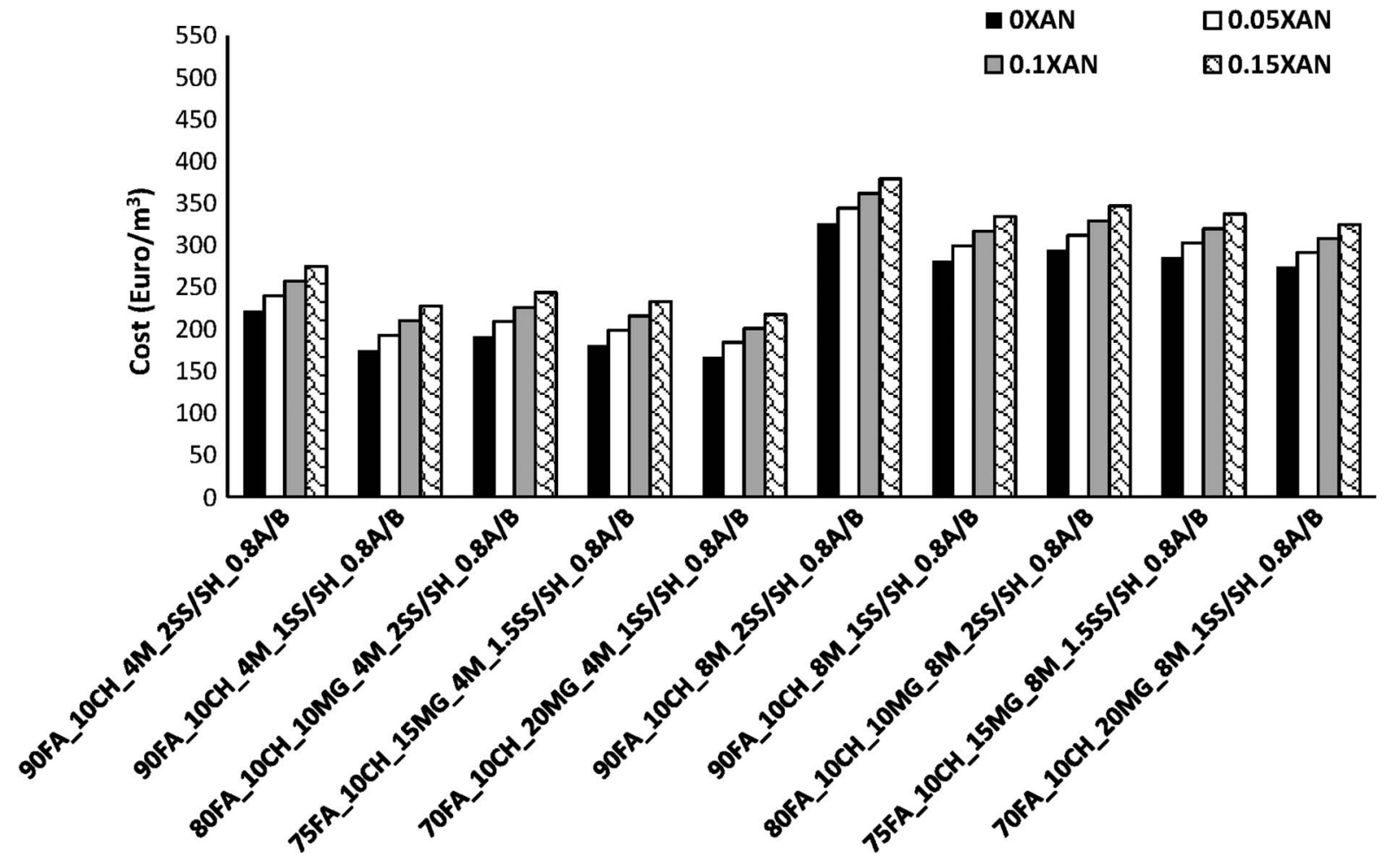

(a)

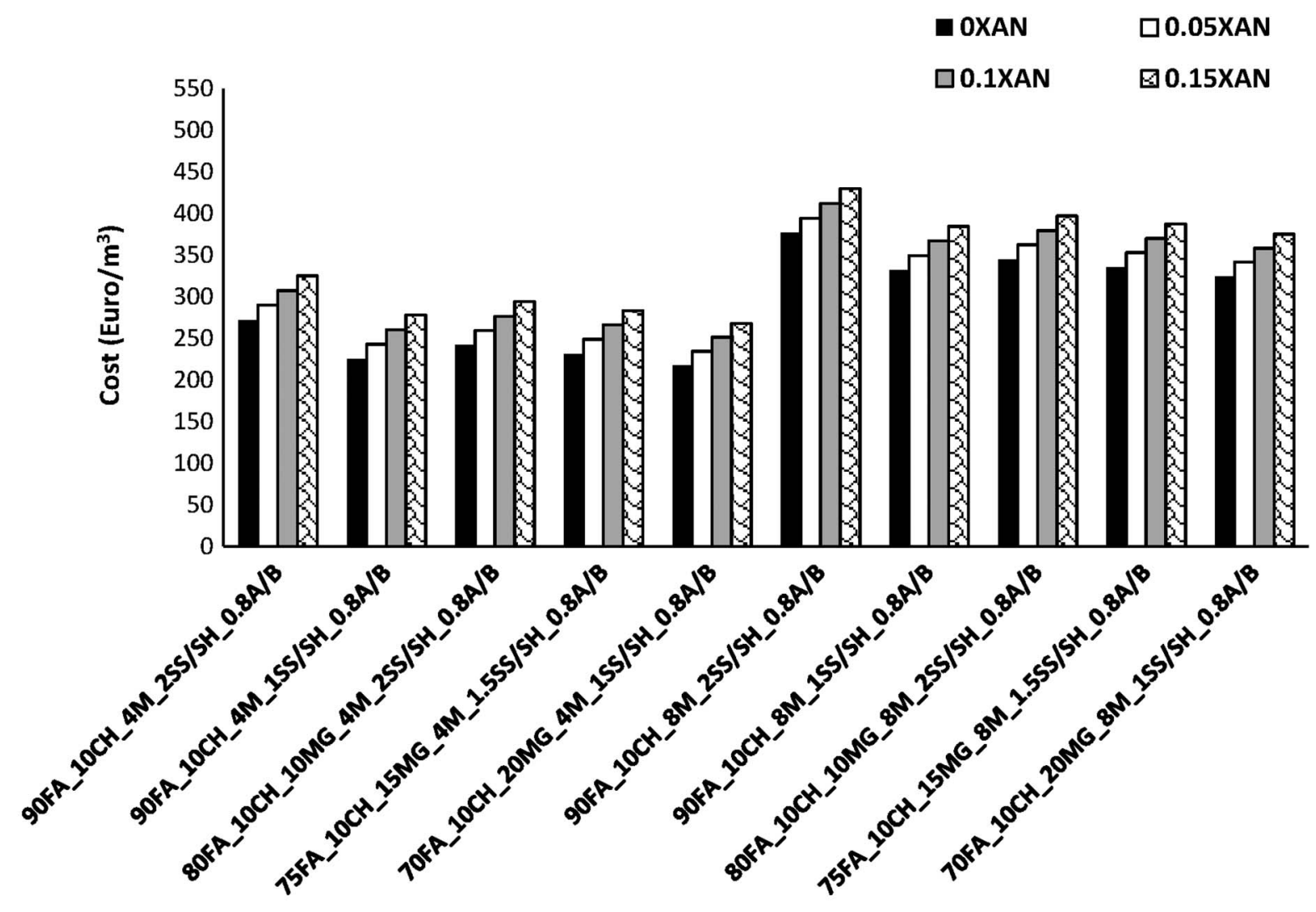

(b)

Fig. 14. Cost of AACB mortars with different xanthan content and cured: (a) at ambient temperature; (b) with $1 \mathrm{~h}$ of heating; (c) with $2 \mathrm{~h}$ of heating; (d) with $3 \mathrm{~h}$ of heating 

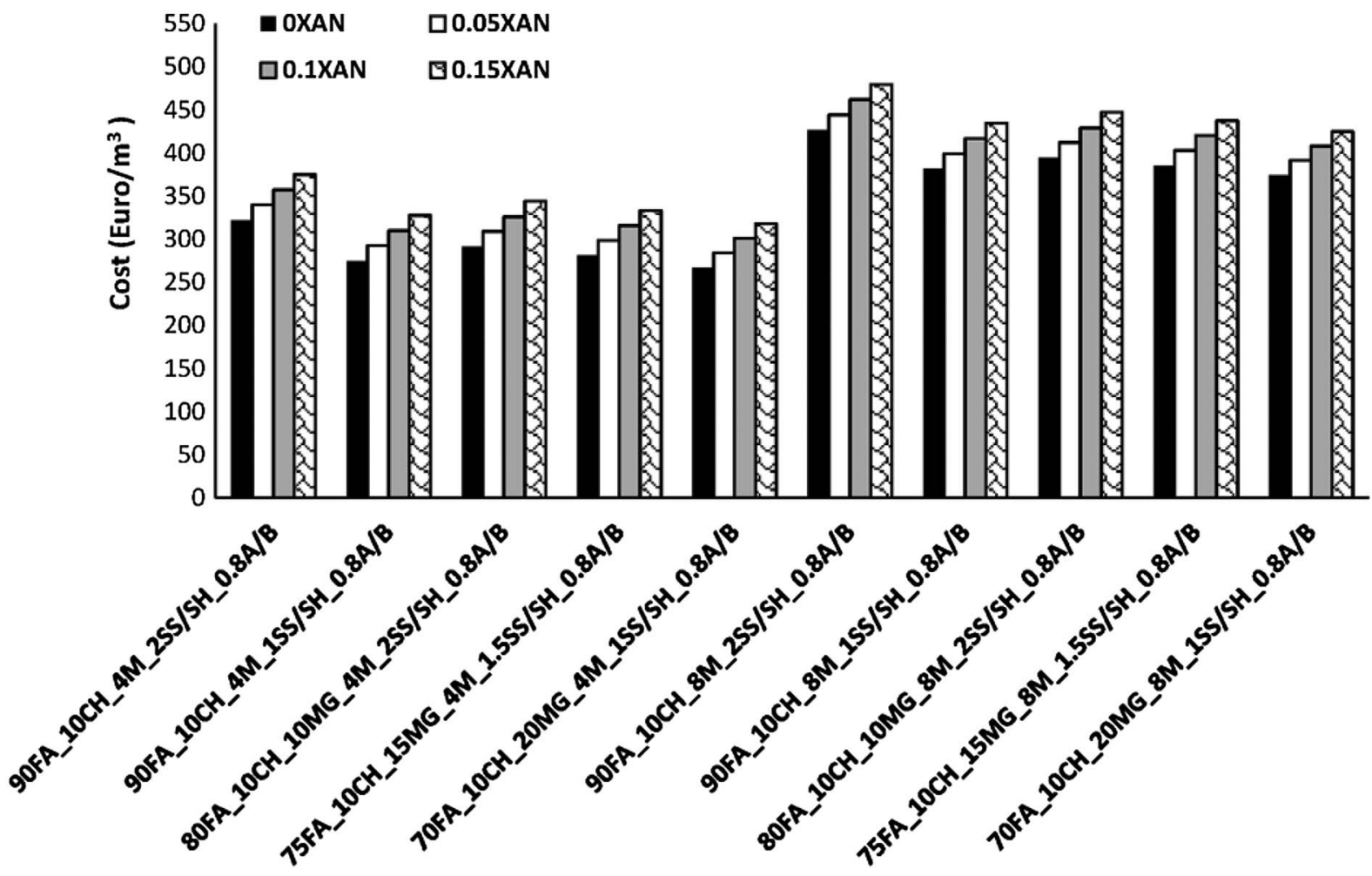

(c)

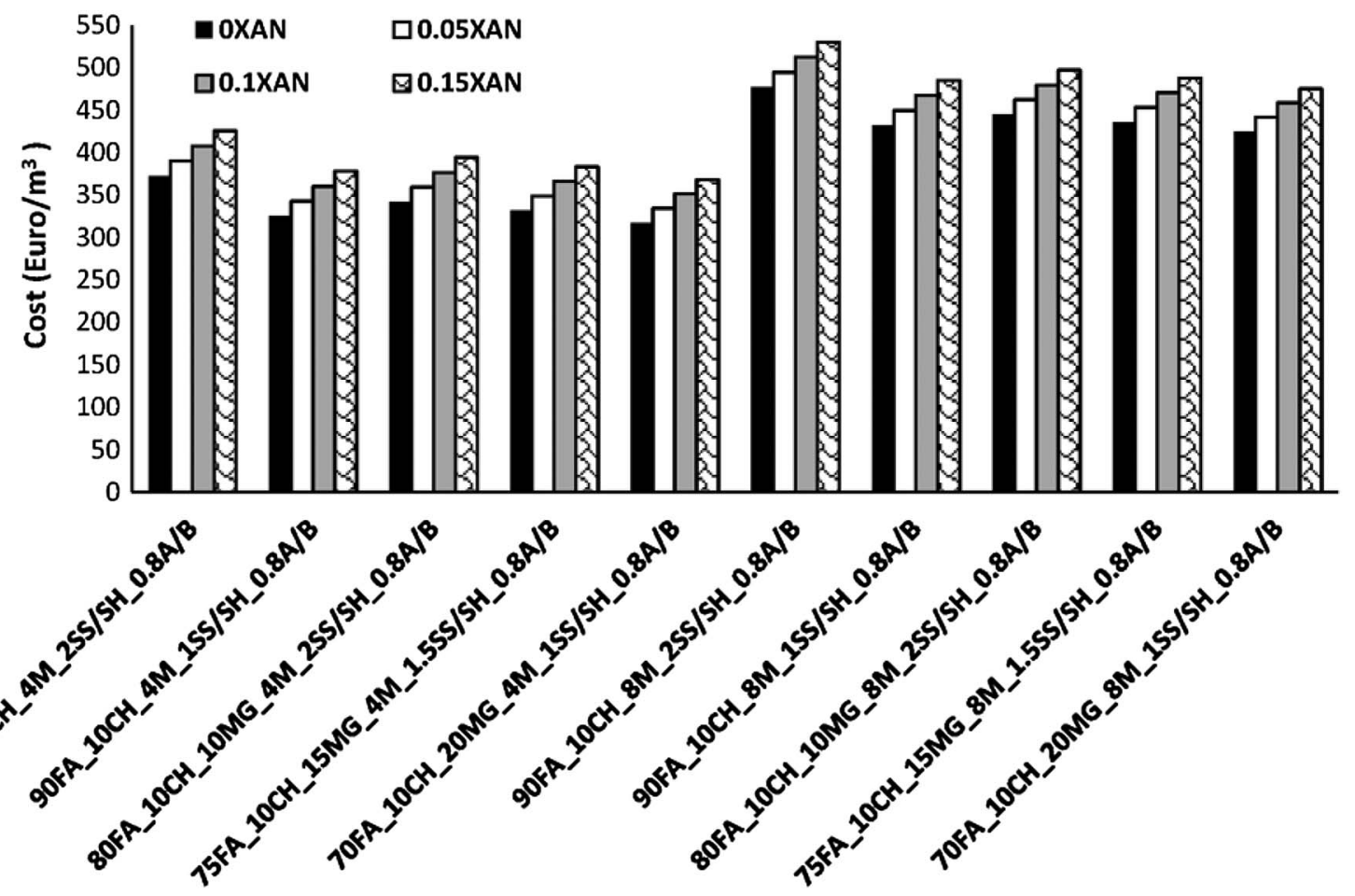

(d)

Fig. 14. (Continued.) 


\section{Acknowledgments}

The authors would like to acknowledge the financial support of the Foundation for Science and Technology (FCT) in the frame of project IF/00706/2014-UM.2.15.

\section{References}

Abdollahnejad, Z., Miraldo, S., Pacheco-Torgal, F., and Barroso Aguiar, J. (2016). "Cost-efficient one-part alkali-activated mortars with low global warming potential for floor heating systems applications." Euro. J. Envir. Civil Eng., 1-18.

Abdollahnejad, Z., Pacheco-Torgal, F., and Félix, T. (2015). "Mix design, properties and cost analysis of fly ash-based geopolymer foam." Constr. Build. Mater., 80, 18-30.

Alonso, S., and Palomo, A. (2001a). "Alkaline activation of metakaolin and calcium hydroxide mixtures: Influence of temperature, activator concentration and solids ratio." Mat. Lett., 47(1-2), 55-62.

Alonso, S., and Palomo, A. (2001). "Calorimetric study of alkaline activation of calcium hydroxide-metakaolin solid mixtures." Cem. Concr. Res., 31(1), 25-30.

American Coal Ash Association. (2016). 〈https://www.acaa-usa.org /Publications/Production-Use-Reports〉 (Jul. 16, 2016).

ASTM. (2015). "Standard specification for coal fly ash and raw or calcined natural pozzolan for use in concrete." ASTM C618-15, West Conshohocken, PA.

Atis, C. D., Görür, E. B., Karahan, O., Bilim, C., Ilkentapar, S., and Luga, E. (2015). "Very high strength (120 MPa) class F fly ash geopolymer mortar activated at different $\mathrm{NaOH}$ amount, heat curing temperature and heat curing duration." Constr. Build. Mater., 96, 673-678.

Bernal, S., Rodríguez, E., Kirchheim, A., and Provis, J. (2016). "Management and valorisation of wastes through use in producing alkaliactivated cement materials." J. Chem. Tech. Biotech., 91(9), 2365-2388.

CEN (European Committee for Standardization). (1999). "Methods of test for mortar for masonry-Part 11: Determination of flexural and compressive strength of hardened mortar." EN1015-11, Brussels, Belgium.

Chindaprasirt, P., and Cao, T. (2014). "Reuse of recycled aggregate in the production of alkali-activated concrete." Handbook of alkali-activated cements, mortars and concretes, F. Pacheco-Torgal, J. Labrincha, A. Palomo, C. Leonelli, and P. Chindaprasirt, eds., WoodHead Publishing, Cambridge, U.K., 519-538.

COM (Communication). (2011). "Roadmap to a resource efficient Europe." COM 571, Brussels, Belgium.

COM (Communication). (2014). "Towards a circular economy: A zero waste programme for Europe." COM 398, Brussels, Belgium.

Garcia-Lodeiro, I., Donatello, S., Fernandez-Jimenez, A., and Palomo, A. (2016). "Hydration of hybrid alkaline cement containing a very large proportion of fly ash: A descriptive model." Materials, 9(8), 605.

Garcia-Lodeiro, I., Fernandez-Jimenez, A., and Palomo, A. (2013). "Hydration kinetics in hybrid binders: Early reaction stages." Cem. Concr. Compos., 39, 82-92.
Gorhan, G., Aslaner, R., and Sinik, O. (2016). "The effect of curing on the properties of metakaolin and fly ash-based geopolymer paste." Composites, Part B, 97, 329-335.

Kim, H., and Kim, Y. (2013). "Relationship between compressive strength of geopolymers and pre-curing conditions." Appl. Microsc., 43(4), $155-163$.

Li, Z., and Zhang, L. (2016). "Fly ash-based geopolymer with kappacarrageenan biopolymer." Biopolymers and biotech admixtures for eco-efficient construction materials, F. Pacheco-Torgal, V. Ivanov, and N. Karak, eds., Woodhead Publishing, Cambridge, U.K., 173-192.

Martinez-Lopez, R., and Escalante-Garcia, E. (2016). "Alkali activated composite binders of waste silica soda lime glass and blast furnace slag: Strength as a function of the composition." Constr. Build. Mater., 119(30), 119-129.

Melbourne Food Depot. (2016). "Suppling premium quality, specialist food ingredients." 〈http://www.melbournefooddepot.com/〉 (Jun. 15, 2016).

Ming, L., Young, H., Al Bakri, M., and Hussin, K. (2016). "Clay geopolymer cements: Structure and properties." Progr. Mater. Sci., 83, $595-629$.

Pacheco-Torgal, F., Abdollahnejad, Z., Camões, C., Jamshidi, M., and Ding, Y. (2012). "Durability of alkali-activated binders: A clear advantage over portland cement or an unproven issue?" Constr. Build. Mater., 30, 400-405.

Pacheco-Torgal, F., Abdollahnejad, Z., Miraldo, S., and Kheradmand, M. (2016). "Alkali-activated cement-based binders (AACB) as durable and cost competitive low $\mathrm{CO} 2$ binders: Some shortcomings that need to be addressed." Handbook of low carbon concrete, Elsevier Science and Tech, Waltham, MA, 195-216.

Payá, J., Monzó, J., Borrachero, M., and Tashima, M. (2014). "Reuse of aluminosilicate industrial waste materials in the production of alkaliactivated concrete binders." Handbook of alkali-activated cements, mortars and concretes, F. Pacheco-Torgal, J. Labrincha, A. Palomo, C. Leonelli, and P. Chindaprasirt, eds., Woodhead Publishing, Cambridge, U.K., 487-518.

Provis, J., et al. (2008). "Will geopolymers stand the test of time?" Ceram. Eng. Sci. Proc., 28(9), 235-248.

Provis, J. L. (2014). "Geopolymers and other alkali activated materials: Why, how, and what?" Mater. Struct., 47(1-2), 11-25.

Rashad, A. (2014). "Recycled waste glass as fine aggregate replacement in cementitious materials based on portland cement." Constr. Build. Mater., 72, 340-357.

Redden, R., and Neithalath, N. (2014). "Microstructure, strength, and moisture stability of alkali activated glass powder-based binders." Cem. Concr. Compos., 45, 46-56.

Van Deventer, J., Provis, J., Duxson, P., and Brice, D. (2010). "Chemical research and climate change as drivers in the commercial adoption of alkali activated materials." Waste Biomass Valorization, 1(1), 145-155.

Wang, W.-C., Chen, B.-T., Wang, H.-Y., and Chou, H.-C. (2016). "A study of the engineering properties of alkali-activated waste glass material (AAWGM)." Constr. Build. Mater., 112, 962-969.

Yu, R., Van Onna, D., Spiesz, P., Yu, Q., and Brouwers, H. (2016). "Development of ultra-lightweight fibre reinforced concrete applying expanded waste glass." J. Cleaner Prod., 112(1), 690-701.

Zhuang, X.-Y., et al. (2016). "Fly ash-based geopolymer: Clean production, properties and applications." J. Cleaner Prod., 125, 253-267. 